\title{
LA AGRICULTURA GALLEGA Y SUS RENDIMIENTOS. Un estudio evolutivo (1700-1850)
}

\author{
Por JOSE MANUEL PEREZ GARCIA \\ Departamento de Historia Moderna \\ Universidad de Santiago
}

Sometemos a la consideración del lector la segunda parte de una encuesta sobre los rendimientos agricolas, iniciada hace algunos años por nosotros(1). La presentación de la fuente aqui utilizada-los patrimonios eclesiásticos-, su crítica y la viabilidad de su empleo ya han ocupado nuestra atención(2), por lo que nos limitaremos ahora a la presentación de los resultados obtenidos, absteniéndonos de innecesarias peticiones.

El área geográfica encuestada en este trabajo corresponde a la Galicia occidental, encuadrada desde la gran dorsal al mar y desde la cuenca del Tambre a la del Miño. Queremos indicar que, aunque los patrimonios eclesiásticos tengan un carácter universal en el mundo católico postridentino, éstos adoptan notables diferencias de una áreas a otras, incluso a la escala reducida en la que trabajamos, en lo que concierne a la información ofrecida. Este handicap determina que no todo el territorio antes acotado ha podido ser estudiado(3) y la muestra retenida se concentra en las zonas de mejor información, siendo así que en otras los datos son inservibles para nuestros fines(4). En total se han retenido unos 300 patrimonios válidos, después de haber tenido que rechazar muchos centenares. Este paquete de escrituras nos ha suministrado información acerca de 3.000 parcelas en 
el total de las dedicaciones agrarias(5), con predominio, claro está,de las cereales. En conjunto se distribuirian asi según sectores geográficos:

Z ONAS $\begin{gathered}\text { Patrimonios } \\ \text { utilizados }\end{gathered} \begin{gathered}\text { Extensión } \\ \text { tierras de cultivo } \\ \text { cerealero (Ha.) }\end{gathered}$

Galicia Litorał(6) .................

93

85,62

Galicia Depresión Meridiana(n) ..........

129

156,54

Galicia Transición a Exterior e Interior(8) ....

82

181,12

TOTAL PATRIMONIOS.........

304

423,28

A las limitaciones geográficas de este estudio hemos de sumar las temporales. Tampoco hemos podido llevar hacia atrás nuestra encuesta por falta de fuentes. Tan sólo hemos obtenido 28 escrituras válidas para la primera mitad del siglo XVIIK(9) de las que 18 corresponden a los años cuarenta. Más allá, los archivos consultados no ofrecen información, tal vez porque la documentación no ha sido conservada, por cuanto parece claro que tales escrituras se realizaban y que se cumplian las ordenanzas de Trento. Creemos que, limitaciones aparte, el espacio geográfico encuestado es representativo de la Galicia Occidental y que el marco temporal aquí retenido es suficiente para alcanzar respuestas válidas. No hay que olvidar que abordamos una etapa en la que se suponen importantes transformaciones en la economla rural del mundo occidental, a veces integradas en lo que quizás pomposamente se conoce como "revolución agraria». El estudiar en qué medida el dinamismo dieciochesco pudo dejar o no alguna huella en Galicia será una de las metas a alcanzar en este modesto trabajo. Creemos que el espejo de los rendimientos es un buen punto de mira y en él deben quedar reflejados los cambios ocurridos en caso de existir.

Queremos también aportar una nueva fuente para el estudio de los rendimientos fuera de las contabilidades señoriales, ya clásicas en este tipo de estudios(10). No conviene olvidar la dificultad de renconstruir largas series temporales para esta variable.

El estado actual de nuestros conocimientos de la agricultura europea de Antiguo Régimen nos ofrece ya un cuadro bastante completo en materia de rendimientos. Son bien conocidos los esfuerzos de Slicher Van Bath para recoger una masa importante de resultados, proplos y ajenos, que le han llevado a señalar el perlodo de 1700 a 1820 como una fase de subida de los rendimientos, en especial para algunos palses como Inglaterra, Bélgica o los Paises Bajos(11). W. Abel confirma esta vision optimista en Alemania(12), en tanto que en Francia e Italia dominan las visiones 
pesimistas(13) aunque no falten evidentes avances, si bien modestos(14). Incluso en las agriculturas de corvea del Este europeo no dejan de registrarse algunas elevaciones en el marco de una economla extensiva poco evolucionada(15).

El panorama de la investigación española sobre rendimientos agrícolas se presenta bastante confuso. La obra de Gonzalo Anes ha iniciado una línea interpretativa pesimista(16), en buena medida continuada por sus disclpulos(17) o seguidores(18). Esta visión negativa presenta hoy notables excepciones a juzgar por las conclusiones de algunos hispanistas(19), pero sobre todo de los geografos(20). Desde luego, no encaja en absoluto la realidad del marco interior castellano con la España periférica en donde las realidades son de signo distinto en muchas ocasiones. As! lo demuestran los estudios de Pierre Vilar para Cataluna(21), de Rafael Benitez para la huerta valenciana(22) o de la Escuela del Prof. Eiras Roel para Galicia, como tendremos ocasión de probar. El panorama de la agricultura española en el siglo XVIII y en materia de rendimientos es más rico y variado del que dejaban entrever aquéllas primeras aproximaciones al tema.

Esta misma dualidad la encontramos en el caso gallego; ésta sucede tanto a nivel de la más reciente publicistica como en su vertiente historiográfica. En el seno de la bibliografía actual cabe mencionar la visión pesimista de Garcla Lombardero(23), así como las aún inéditas conclusiones de la gran Tesis Doctoral de Ramón Villares(24). Esta interpretación casi inmovilista de la agricultura gallega de los tiempos modernos contrasta profundamente con la mayorla de los principales aportes de la escuela de ruralistas del Profesor Eiras Roel. Tanto el estudio de los diezmos(25), como las primeras cifras evolutivas de rendimientos obtenidas(26), ponen en duda la supuesta falta de capacidad innovadora de esta estructura económica, incluso en las áreas interiores menos dinámicas, como sucede con El Burón(27). La obra de geografos de la categorla de un Bouhier ahondan en esta última interpretación(28) para el marco general de Galicia y confirman aquellos estudios precedentes sobre áreas comarcalizadas.

Ni que decir tiene que esta postura dual no constituye ninguna novedad y que por tanto la polémica es vieja. La agricultura gallega de Antiguo Régimen ya fue analizada por sus contemporáneos, sobre todo a lo largo de los siglos XVIII y XIX en los que existe una relativa abundancia de testimonios y, con frecuencia, nos dejaron lúcidos estudios sobre ella. Una visión muy somera podría llevarnos a una dicotomia en la que quizás no todos los ruralistas estarian concordes:

a) Un grupo, que para nosotros serla minoritario, por lo general del interior gallego, ve su agricultura de una manera muy pesimista. Estos hombres lamentan reiteradamente la invasión de comunales, atacan las excesivas roturaciones, añoran la pérdida del equilibrio entre agricultura y 
ganadería a consecuencia de ellas, insisten sobre nuestro retraso con relación a Europa y España, etc.(29). Su óptica, al extender sus apreciaciones a todo el solar gallego, es con frecuencia limitada y son incapaces de percibir las ventajas de una agricultura intensiva(30), tal vez fascinados por el modelo inglés.

b) Otro grupo de autores que creemos mayoritario, nos relata, por el contrario, la gran habilidad y laboriosidad de los campesinos gallegos(31), describe con énfasis el sistema intensivo(32), limita el alcance del barbecho en Galicia(33), contempla las ventajas de este sistema(34), etc. Cuando alguno de estos autores se detiene a hacer comparaciones lo acompaña no pocas veces de cálculos estadísticos y no duda de la superioridad de la agricultura gallega dentro del conjunto españo|(35), aunque reconoce la superioridad de las más evolucionadas del contexto europeo. Es un grupo mucho más próximo al modelo de los Países Bajos que consideran más acomodado para Galicia.

Nuestro trabajo no pretende sino romper una lanza a favor de estos últimos. Para ello nos apoyaremos en pruebas cuantitativas controladas, tal y como exige una historia económica rigorista, abandonando la línea impresionista, al menos como base dominante de sostén de conclusiones. No podía ser de otro modo dada la división tan acusada de pareceres existente. No debemos perder de vista tampoco el limitado alcance geográfico de la muestra manejada, quizás no mayor a 1/3 del total del solar gallego. Es por ello que nos guardaremos de hacer extensible estos resultados al resto de Galicia.

I) LA EVOLUCION DE LOS RENDIMIENTOS CEREALEROS

Areas geográficas:

a) La Galicia Litoral de las Rías Bajas

El análisis bidecenal(36) de nuestros datos quedaría asi:

Años

N. ${ }^{\circ}$ Parcelas
Extensión en ferrados (f)
Rendimientos medios ponderados

$\begin{array}{lrlll}1 .^{\mathrm{a}} \text { mitad s. XVIII } \ldots & 61 & 173,75 & 1.151 & 6,62 \\ 1750-69 \ldots \ldots \ldots & 76 & 225,5 & 1.511,5 & 6,70 \\ 1770-89 \ldots \ldots \ldots & 65 & 159,25 & 1.153 & 7,24 \\ 1790-1809 \ldots \ldots \ldots & 151 & 312,25 & 2.358,5 & 7,55 \\ 1810-29 \ldots \ldots \ldots & 123 & 294,75 & 2.418,5 & 8,21 \\ 1830-49 \ldots \ldots \ldots & 66 & 195,75 & 1.943 & 9,93\end{array}$


La interpretación de la tabla no puede ser más clara. Sobre un alto nivel de partida próximo a $7 \times 1$, sinónimo de una agricultura evolucionada(37), y después de superar los malos momentos de los años sesenta en los que asistimos a la proliferación de malas cosechas, esta costa gallega parece iniciar una etapa de manifiesta expansión. Podríamos señalar dos fases en ella: una primera de ascensión lenta desde 1770 a 1809 y una auténtica explosión a partir de 1810 . En conjunto se habría pasado de un nivel inferior a $7 \times 1$ para alcanzar unos rendimientos medios próximos a $10 \times 1$ en superficie.

Si tradujésemos a $\mathrm{HI} / \mathrm{Ha}$ esta anterior elevación y tomásemos amplios periodos de contraste obtendriamos:

$$
\begin{array}{ll}
1{ }^{a} \text { mitad del s. XVIII . . . . . . . } & 20,31 \mathrm{HI} / \mathrm{Ha} \\
1820-1849 \ldots \ldots \ldots \ldots \ldots \ldots \ldots \ldots & 28,60 \mathrm{HI} / \mathrm{Ha}
\end{array}
$$

Sea pues una subida nada desdeñable del $40 \%(38)$. Se constata así el dinamismo de estas culturas costeras del sudoeste gallego asi como el virtuosismo que pueden lograr algunas agriculturas minifundistas(39). Tampoco podemos afirmar que hacia mediados del siglo XIX se hubiesen alcanzado techos insuperables en el seno de esta agricultura tradicional(40). En cualquier caso, estos avances son tanto más significativos si tenemos en cuenta los altos parámetros ya alcanzados a mediados del setecientos.

\section{b) La Galicia de la Depresión Meridiana}

Con las mismas bases precedentes he aquí los resultados:

Años N. ${ }^{0}$ Parcelas Extensión (f) Producción (f)

Rendimientos medios ponderados

\begin{tabular}{lrlll}
\hline $1 .{ }^{a}$ mitad s. XVIII $\ldots$ & 46 & 407,5 & 2.845 & 6,10 \\
$1750-69 \ldots \ldots \ldots \ldots$ & 129 & 123 & $2.654,5$ & 6,27 \\
$1770-89 \ldots \ldots \ldots \ldots$ & 185 & 567,5 & $3.332,5$ & 5,87 \\
$1790-1809 \ldots \ldots \ldots$ & 155 & 325,5 & $2.357,5$ & 7,24 \\
$1810-29 \ldots \ldots \ldots \ldots$ & 197 & 424,25 & 3.402 & 8,02 \\
$1830-49 \ldots \ldots \ldots \ldots$ & 150 & 341 & 2.954 & 8,66
\end{tabular}

El cuadro que nos presenta esta geografía de los valles bajos occidentales no difiere gran cosa del modelo anterior. Parece evidente también el alto nivel de partida ahora en torno a $6 \times 1$, al parecer bien superior a cálculos disponibles en épocas precedentes(41) y concordantes con los alcanzados por otros estudios para estas áreas ${ }^{(42)}$. Sin embargo, conviene anotar dos apreciaciones: 
-Que el nivel de rendimientos es inferior al que hemos visto con anterioridad para las demarcaciones litorales. 1790.

-Que el salto de los rendimientos parece datar de fechas proximas a

Sea un retraso de unos 20 años frente al grupo precedente.

En cualquier caso, el ascenso ha sido significativo y de un nivel de $6 \mathbf{x}$ 1 se ha pasado a unos rendimientos en superficie ligeramente superiores a $8 \times 1$. Si lo redujéramos a $\mathrm{HI} / \mathrm{Ha}$ podríamos resumir el mencionado avance en:

$\begin{array}{ll}1 .{ }^{\text {a }} \text { mitad del siglo XVIII } \ldots \ldots \ldots & 18,14 \mathrm{HI} / \mathrm{Ha} . \\ 1820-1849 \ldots \ldots \ldots \ldots \ldots \ldots \ldots & 26,20 \mathrm{HI} / \mathrm{Ha} .\end{array}$

Esto supone una elevación del $44,4 \%$, algo superior al anterior y que aproxima bastante estas agriculturas, tal y como sucede en la actualidad(43).

Los techos, pues, de mediados del siglo XIX tampoco fueron insuperables y estas fértiles tierras de los valles fluviales fueron capaces de lograr, eso sí con algún retraso, un nivel de productividad similar al precedente en pleno siglo $\mathrm{XIX}$.

c) La Galicia de la Transición al Interior e Interior

Resultados que hemos obtenido:

Años N. ${ }^{\circ}$ Parcelas Extensión (f) Producción (f) $\begin{gathered}\text { Rendimientos } \\ \text { medios } \\ \text { ponderados }\end{gathered}$

\begin{tabular}{lrlll}
\hline 1. $^{\mathrm{a}}$ mitad s. XVIII $\ldots$ & 78 & 745,5 & 4.269 & 5,73 \\
$1750-69 \ldots \ldots \ldots \ldots$ & 80 & 349,5 & 1.727 & 4,94 \\
$1770-89 \ldots \ldots \ldots \ldots$ & 90 & 471 & 2.428 & 5,15 \\
$1790-1809 \ldots \ldots \ldots$ & 89 & 368,5 & 2.533 & 6,87 \\
$1810-29 \ldots \ldots \ldots \ldots$ & 98 & 300 & 1.907 & 6,36 \\
$1830-49 \ldots \ldots \ldots \ldots$ & 166 & 645 & $5.101,5$ & 7,91
\end{tabular}

El esquema es ahora un poco más confuso y no ofrece esa casi regular subida de las zonas precedentes. La explicación quizás venga dada por el hecho de ser una agricultura más sometida a las oscilaciones climáticas que las anteriores, dado su estadio más arcaizante. El recuerdo de periodos malos dejaría aquí una huella más profunda y marcada y esto explicaría muy bien las bajas cifras de los años setenta-menos marcadas pero visibles en los casos anteriores-fiel reflejo de la nefasta década anterior; lo mismo ocurriría en 1810-19 con relación a las malas cosechas de comienzos del siglo XIX. De todas maneras, la elevación de los rendimien- 
tos parece clara también y se habria producido asimismo en dos tirones: uno a partir de los años noventa, que cierra una larga fase de estancamiento; otro a partir de 1820 , más importante y parece que definitivo(44). El aumento ha sido importante y de un nivel próximo a $5 \times 1$ se ha pasado a otro claramente superior a $7 \times 1$.

Si nos remitiéramos a la relación $\mathrm{HI} / \mathrm{Ha}$ el camino recorrido por estas comarcas sería:

$$
\begin{array}{ll}
1 .^{a} \text { mitad del siglo XVIII } \ldots \ldots \ldots & 15,96 \mathrm{Hl} / \mathrm{Ha} . \\
1820-1849 \ldots \ldots \ldots \ldots \ldots \ldots \ldots & 22,18 \mathrm{Hl} / \mathrm{Ha} .
\end{array}
$$

En definitiva, estamos ante una subida nada despreciable del $39 \%$ pareja a las anteriores y que ha llevado a estas áreas a un nivel de rendimientos muy aceptable en la primera mitad del siglo $X \mid X^{45}$. En fases posteriores completaría una elevación que en su conjunto seria próxima al 100 $\%$ desde mediados del siglo XVIII a mediados del siglo XX, como sucedió en las zonas litorales(46).

Este análisis geográfico ha puesto de manifiesto una general elevación de los rendimientos en el conjunto de las áreas estudiadas. Todas las zonas tienen unas ganancias parejas de 2 a 3 puntos y que equivalen a una elevación que se podría enmarcar en un porcentaje próximo al $40 \%$.

Podriamos afinar aún un poco más esta transformación analizando los intervalos de rendimientos(47). Un contraste entre 1700-1789 y 1790-1849 nos permite ver, a través de la curva y de los datos porcentuales, que los cambios fueron escasos en las comarcas costeras. Claro que la concentración de los valores entre 3 y 8 , dominante en el primer período con un $80 \%$ de los casos, pierde cerca de un $10 \%$ que pasa a engrosar los intervalos superiores en la segunda fase. Por el contrario, en las demás áreas las variaciones son más acusadas: sobre una curva de valores más arcaica con dominio clarísimo de los rendimientos 5 y $6 \times 1$, se pasa a otra estructura en la que, o bien la primacia se transfiere al intervalo siguiente (tierras de valles) o bien se pierde el viejo predominio (zonas interiores). El cambio ha sido acusado sobre todo en estas últimas áreas, las más arcaicas inicialmente: se parte de una situación en la que el $79 \%$ de los rendimientos se situan entre 3 y 6 y se llega a otra en la que este intervalo se reduce al $33 \%$ en beneficio de los superiores. Es asi que en la segunda fase el $6 \%$ de los rendimientos se encuadran en una banda del 5 a $10 \times 1$.

Resumiendo, pues, sobre una realidad de partida muy desigual con un claro avance de las tierras costeras, símbolo de un modelo más evolucionado, y en la que los valores dominantes en todas las zonas son de 5 y 6 $\times 1$, se llega a otra caracterizada por una neta aproximación del abanico de los intervalos de rendimientos en las tres demarcaciones. 


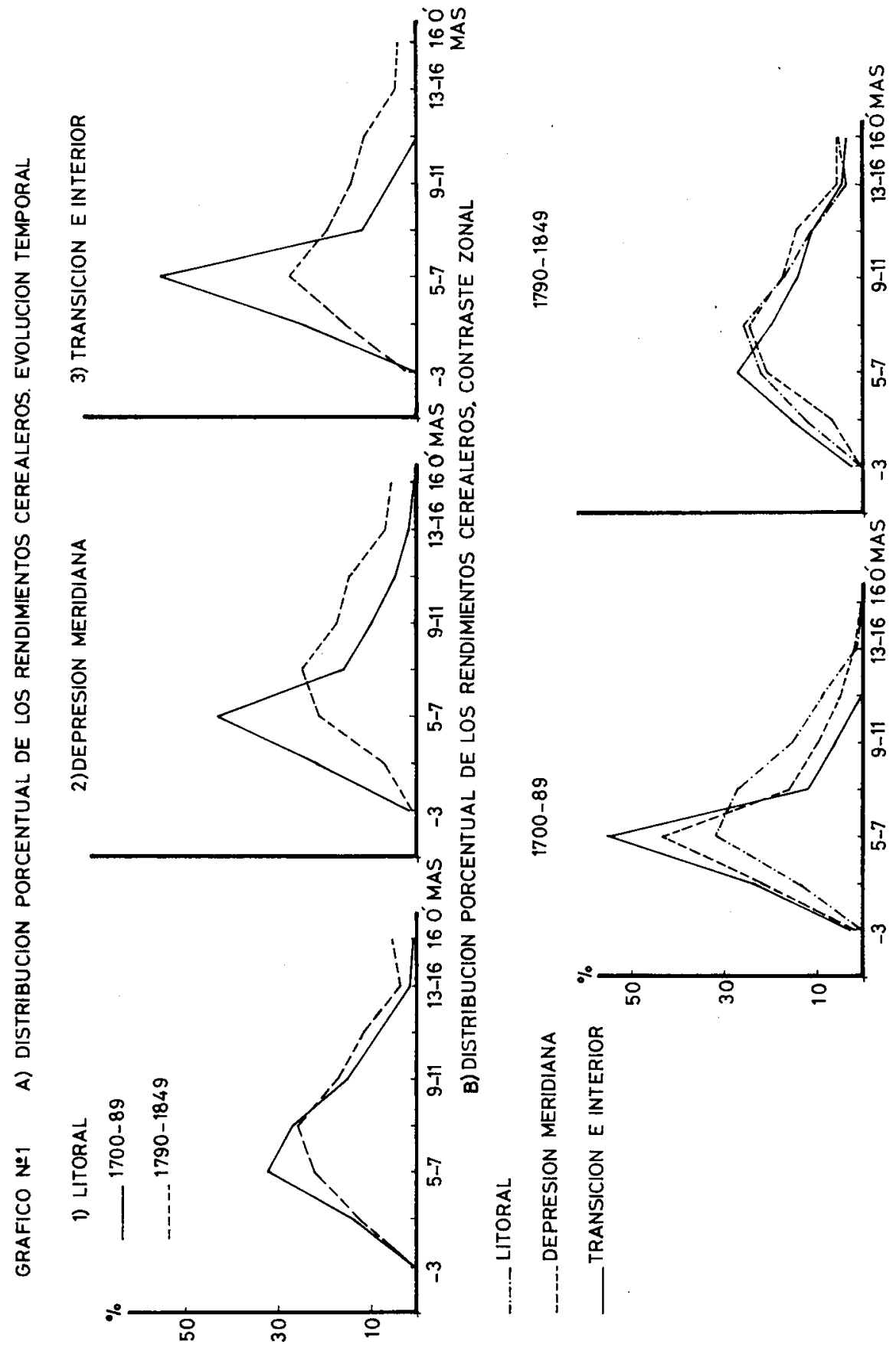


Es claro, a la luz de estos rendimientos, que la Galicia situada al occidente de la gran dorsal ha vivido en esta fase cambios profundos que arrancando de la costa van ganando de una manera progresiva las tierras interiores. Creemos que la intensificación y el perfeccionamiento del viejo sistema, reflejados en los rendimientos, han mejorado ostensiblemente a lo largo de este periodo estudiado. También se desprenderia de nuestro análisis(48) que la virtualidad de esta agricultura comenzaría a manifestarse por las comarcas litorales meridionales. Sobre un nivel ya muy evolucionado hacia mediados del siglo XVIII se registra un claro progreso a partir de 1770; entonces, el umbral de $7 \times 1$ es rebasado por primera vez y de manera definitiva, ya que desde entonces la ascensión es clara y sostenida. En las demás demarcaciones el movimiento ascendente se retrasa quizás unos $20 \circ 30$ años y no se consolida hasta los años noventa y es ahora en los valles inferiores donde se superan por primera vez y de manera definitiva los rendimientos medios de los años cincuenta. En las tierras del interior también se hace visible el avance desde los años noventa, pero el umbral del $7 \times 1$ y la consolidación de los altos rendimientos no parece lograrse hasta los años veinte del siglo XIX.

A medida que nos adentramos en el interior gallego, cada una de las áreas demarcadas repite y alcanza unos rendimientos que se han dado con un adelanto de 20 o 30 años en el área precedente. Dicho de otra forma, los valles altos occidentales alcanzan el nivel de los rendimientos costeros con medio siglo de retraso, en tanto que las distancias tienden a aminorarse, al menos de una manera relativa. Las ventajas costeras se mantendrán siempre hasta nuestros días pero su ventaja sólo se mantiene al nivel de las cantidades brutas.

Podriamos finalizar este primer acercamiento a los rendimientos con lo que sería nuestra curva general evolutiva de los rendimientos de la Galicia Occidental(49). Veamos los datos:

\begin{tabular}{ccccccc}
\multicolumn{1}{c}{ Años } & $\begin{array}{c}\text { N. }{ }^{\circ} \\
\text { Patrs. }\end{array}$ & $\begin{array}{c}\text { N. }{ }^{\circ} \\
\text { Parcs. }\end{array}$ & $\begin{array}{c}\text { Extensión } \\
\text { (f) }\end{array}$ & $\begin{array}{c}\text { Producción } \\
\text { (f) }\end{array}$ & $\begin{array}{c}\text { Rendimientos } \\
\text { medios } \\
\text { ponder.(50) }\end{array}$ & $\begin{array}{c}\text { Rendimientos } \\
\text { medios } \\
\text { simples }\end{array}$ \\
\hline $1 .{ }^{\text {a } 1 / 2 ~ s . ~ X V I I I ~ . ~}$ & 28 & 185 & $1.326,75$ & 7.805 & 5,88 & 6,15 \\
$1750-59 \ldots \ldots$ & 15 & 174 & 642,5 & 3.675 & 5,72 & 6,12 \\
$1760-69 \ldots \ldots$ & 19 & 125 & 355,5 & 2.198 & 6,22 & 6,18 \\
$1770-79 \ldots \ldots$ & 28 & 161 & 622,25 & 3.394 & 5,55 & 5,85 \\
$1780-89 \ldots \ldots$ & 25 & 180 & 586,5 & $3.519,5$ & 6,00 & 6,35 \\
$1790-99 \ldots \ldots$ & 31 & 200 & 474,25 & 3.395 & 7,16 & 7,13 \\
$1800-09 \ldots \ldots$ & 32 & 195 & 532 & 3.854 & 7,24 & 7,28 \\
$1810-19 \ldots \ldots$ & 41 & 251 & 506,25 & 3.373 & 7,45 & 7,39 \\
$1820-29 \ldots \ldots$ & 36 & 167 & 512,75 & $3.954,5$ & 7,71 & 7,67 \\
$1830-39 \ldots \ldots$ & 29 & 226 & 608 & 5.156 & 8,48 & 8,71 \\
$1840-49 \ldots \ldots$ & 20 & 156 & 573,75 & $4.842,5$ & 8,44 & 9,23 \\
\hline
\end{tabular}

TOTALES . . . $304 \quad 2.020 \quad 6.729,5 \quad 45.566,5$ 
A) EVOLUCION DE RENDIMIENTOS POR AREAS GEOGRAFICAS

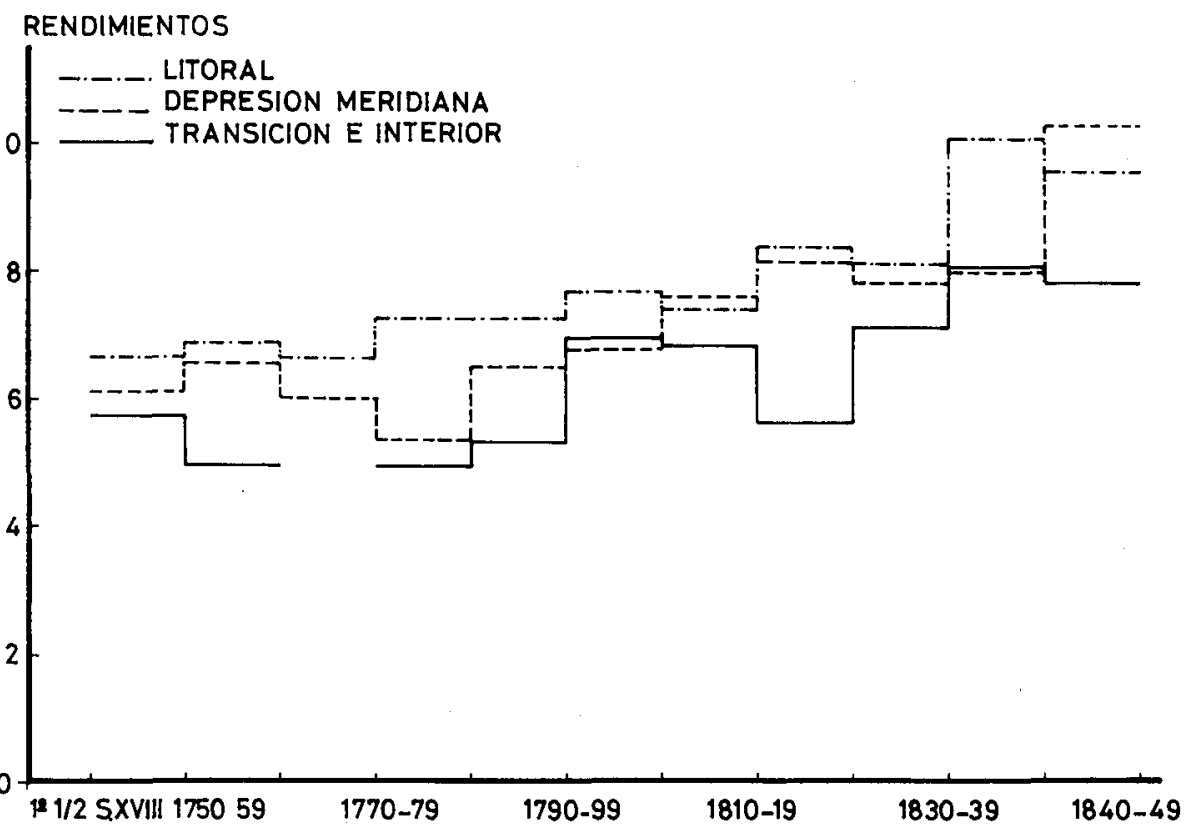

B) EVOLUCION DE RENDIMIENTOS. CURVA GENERAL GALICIA OCCIDENTAL

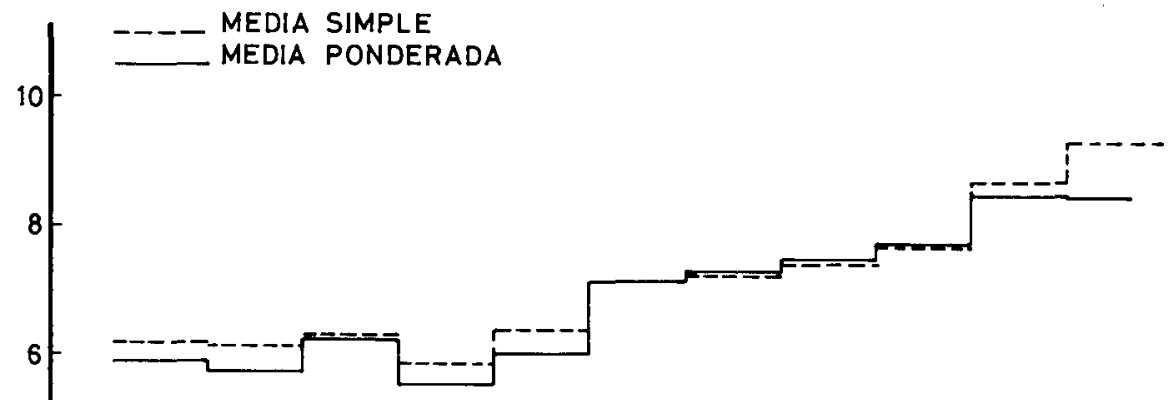

0 
Considerando esta tabla en perídos semiseculares, quedaría así nuestro resumen global:

$\begin{array}{lrrllll}1^{\mathrm{a}} 1 / 2 \text { s. XVIII . } & 28 & 185 & 1.326,75 & 7.805 & 5,88 & 6,15 \\ \text { 2. }^{\mathrm{a}} 1 / 2 \text { s. XVIII . } & 118 & 840 & 2.670 & 16.181,5 & 6,06 & 6,34 \\ \text { 1. }^{\mathrm{a}} 1 / 2 \text { s. XIX .. } & 158 & 995 & 2.732,75 & 21.580 & 7,90 & 8,06\end{array}$

Las cifras nos habian de un largo periodo de estabilidad en los rendimientos que Ilegaria hasta fines del siglo XVIII. La débil muestra de la primera mitad de esta centuria y el predominio de casos de los años cuarenta nos impiden situar el comienzo de esta fase estable. Queda claro el ascenso casi perfecto desde los años noventa quizás no cortado hasta mediados del siglo XIX. Entre 1790 y 1850 asistimos a una fase brillante que elevaria de una manera muy destacable la productividad cerealera por unidad de superficie(51), lo que hacía posible a este clero patrimonialista espectante alcanzar notables cotas de rentas en sus arrendamientos a corto plazo(52). El conjunto de la elevación por nosotros alcanzada habria que situarla entre un 31 y un $34 \%$ según las medias utilizadas contrastando las cifras globales de la primera mitad del siglo XVIII con las de la primera mitad del siglo XIX. Si se prefiere, entre un 48 y un $51 \%$ comparando los años cincuenta del siglo XVIII con los cuarenta del siglo XIX quizás un poco inflado por la pérdida del diezmo eclesiástico. Esta elevación importante de la productividad para este conjunto gallego y que cifraríamos dentro de un intervalo del 33 y $40 \%$, plantea serios problemas al contrastar de una manera abierta con otros resultados disponibles(53). En cualquier caso, de admitirse esta progresiva elevación de la productividad durante el período indicado, creemos que sería menos forzada la explicación de la elevación de la población durante esta fase(54) en la que, por otra parte no se registra un importante éxodo migratorio, ni graves crisis de subsistencias, al contrario de lo que ocurre en el mundo castellano(55).

Podríamos acercarnos un poco más a partir de nuestros patrimonios y ver a través de sus declaraciones cómo han evolucionado los rendimientos por superficie según la dedicación cerealera del terrazgo, ateniéndonos a las producciones especificas en ellos reseñadas. Los resultados, a veces con un número de casos poco representativos, serían: 


\begin{tabular}{|c|c|c|c|c|}
\hline \multirow[b]{2}{*}{ ZONAS } & \multicolumn{2}{|c|}{ 1700-1769 } & \multicolumn{2}{|c|}{ 1820-1849 } \\
\hline & $\begin{array}{c}\mathbf{N} \mathbf{0}^{\circ} \\
\text { Parcelas }\end{array}$ & $\begin{array}{l}\text { Rendimientos } \\
\text { medios }\end{array}$ & $\begin{array}{c}N{ }^{\circ} \\
\text { Parcelas }\end{array}$ & $\begin{array}{l}\text { Rendimientos } \\
\text { medios }\end{array}$ \\
\hline Litoral . ............ & 7 & 4,42 & 21 & 6,28 \\
\hline Depresión Meridiana . . & 17 & 4,62 & 10 & 6,89 \\
\hline Transición e Interior ... & 13 & 4,69 & 31 & 7,58 \\
\hline B) CENTENO & & & & \\
\hline Litoral . & 18 & 6,49 & - & - \\
\hline Depresión Meridiana .. & 50 & 5,48 & 31 & 9,93 \\
\hline Transición e Interior ... & 61 & 5,61 & 65 & 6,52 \\
\hline C) MAIZ & & & & \\
\hline Litoral $\ldots \ldots \ldots \ldots$ & 56 & 7,34 & 104 & 9,98 \\
\hline Depresión Meridiana .. & 120 & 6,62 & 180 & 8,36 \\
\hline Transición e Interior ... & 44 & 5,80 & 84 & 8,22 \\
\hline
\end{tabular}

Creemos que los resultados son bien elocuentes a pesar de la exigüidad de las cifras manejadas en algunas especies. Queda claro que el ascenso fue general en todas las especies cultivadas y en todas las áreas señaladas. Expresan con seguridad el triunfo de una hábiles rotaciones y de una creciente acomodación entre agricultura y ganadería, como trataremos de ver en su momento y que tal vez permitió un más eficaz abonado. Mientras los rendimientos del trigo situados en torno a 4,5 $\times 1$ en la primera fase se aproximan a $7 \times 1$ en la segunda, en el centeno el avance es más claro aunque más confuso. El gran triunfador es el maíz que, partiendo de unos niveles ya muy notorios de 6 a $7 \times 1$ llegaria a unas cotas medias situables en 8 a $10 \times 1$. Es te éxito del maiz nada debe sorprendernos; los propios contemporáneos lo vieron con claridad meridiana(56).

Por último, intentaremos una aproximación a los rendimientos por semilla(57). Se trata de cálculos aproximativos por cuanto conocemos las cantidades producidas pero las semillas empleadas son más difíciles de precisar. Contamos para ello con las Respuestas Generales del Catastro de Ensenada y carecemos de datos posteriores con lo que la precisión exacta de esta variable es imposible(58). Los resultados serían (en ferrados): 
A) TRIGO

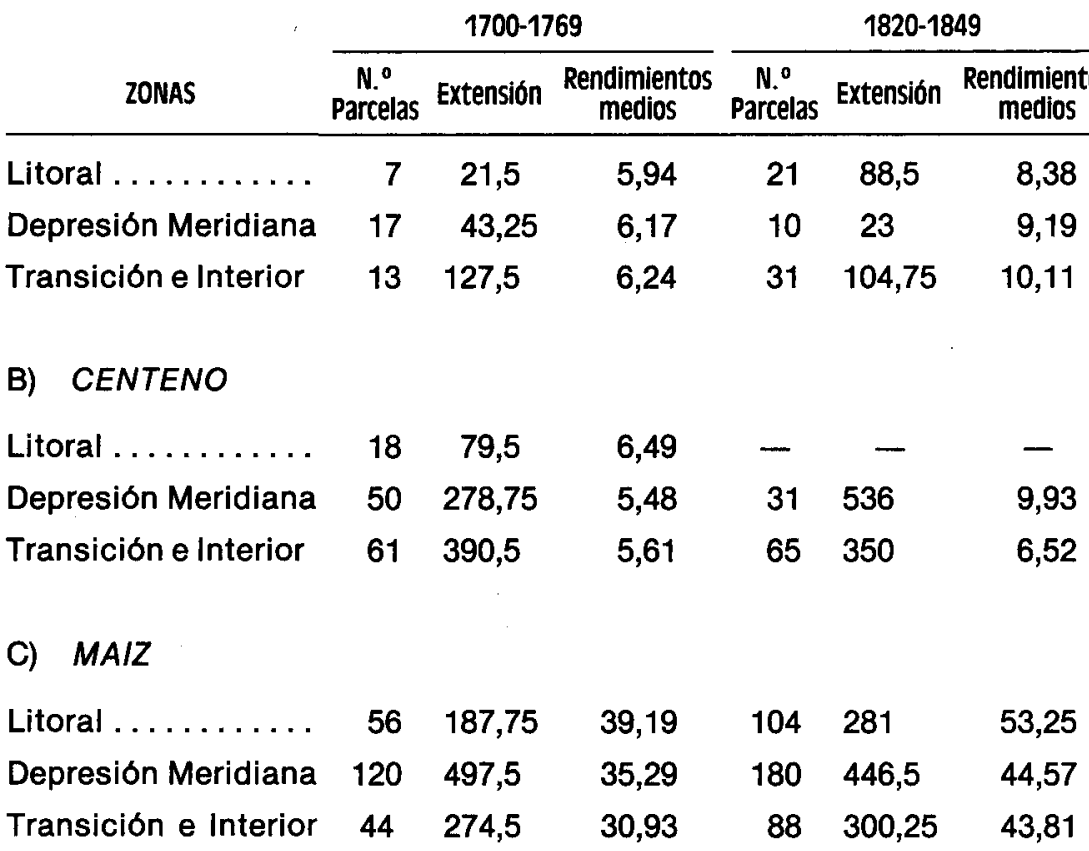

Una vez más confirmamos el avance y alta productividad de esta agricultura minifundista. En trigo y centeno sobre unos rendimientos de partida de 5 a $6 \times 1$ pasamos a otros situados de forma dominante entre 8 y $10 \times$ 1. Sin embargo, comprobamos que la gran ventaja de este sistema se confirma una vez más sobre el maíz. Sus rendimientos por semilla cuadriplican como mínimo la rentabilidad alcanzada por los cereales tradicionales e incluso puede multiplicarla por 6 o 759). Puede apreciarse asimismo que es precisamente sobre el maíz donde queda reflejada esa mayor productividad a medida que nos acercamos al litoral; sin duda, las ventajas climáticas juegan aquí un destacado papel. Pero puede apreciarse también cómo en el segundo cuarto del siglo XIX estos altos rendimientos obtenidos para el maíz se localizan ya en las zonas interiores, lo que habla por si solo del perfeccionamiento de su cultivo en estas demarcaciones.

\section{II) LA EVOLUCION DE LOS RENDIMIENTOS VITICOLAS}

No son pocas las ocasiones en las que nuestros patrimonios ofrecen datos de producción de la vid. Rara es la escritura patrimonial de una 
comarca costera o de valles inferiores que no ofrezca algún parral o parcela en cepa redonda entre sus diversas partidas. Más allá de estas tierras y a medida que nos adentramos en el interior, como es normal, la vid se vuelve rara y por ello hemos preferido limitar nuestros cálculos a aquellas zonas en una tabla común a fin de operar con cifras representativas.

Queremos indicar también, que la fijación del producto bruto, indispensable para los cálculos, es más difícil de precisar en nuestra fuente que en el anterior caso de los cereales. Con frecuencia, nos indica el producto neto que recibirá el patrimonialista y en ocasiones ofrece el producto bruto del que se le deducen las rentas y los gastos de cultivo para derivar en el producto neto; no obstante, en ocasiones la diferencia entre producto bruto y producto neto no queda clara en la fuente. Por último, hay ocasiones en que nos suministra las medias del cultivador o colono en un claro sistema de aparcería a la mitad de la producción. No obstante, la fijación de esos parámetros, necesarios para reconstruir nuestros datos, no es tan clara ni tan regular como en el caso cerealero que casi siempre queda determinado en un $50 \%$, sea el equivalente a rentas, semillas y gastos de cultivo. En la vid falta el factor semilla y esto complica los datos. ¿En qué medida se compensa esta falta con unos mayores gastos de cultivo y con una mayor presión de la renta con relación al caso cerealero?. Por todo ello hemos realizado un doble cálculo que viene justificado por la naturaleza de los datos.

a) En el primer caso los gastos de cultivo, rentas y contribuciones quedan estimadas en $1 / 3$ del producto bruto, dado que en 19 casos claros patrimoniales se establece este baremo. Cuado sólo disponemos de la producción neta hemos considerado que ésta suponía el $67 \%$ y hemos deducido a partir de aquí el producto bruto.

b) En el segundo cálculo, los gastos de cultivo, rentas y contribuciones quedan establecidas en la mitad por cuanto en 30 ejemplos controlados así se hace. Como en el caso anterior, cuando se tiene sólo la producción neta, ésta ha sido duplicada para establecer el producto bruto de cada parcela(60).

Es claro, que estos presupuestos solo afectan a aquellas piezas que únicamente ofrecen la producción neta. Cuando disponemos del producto bruto en la propia fuente, éste ha sido retenido para ambos cálculos. Por estas razones y por la divergencia de medidas de superficie y capacidad(61), los datos que presentamos hay que tomarlos como una simple aproximación. Veamos estos resultados (en moyos): 


\begin{tabular}{|c|c|c|c|c|c|c|c|}
\hline AÑOS & $\begin{array}{c}\text { N. }{ }^{\circ} \\
\text { Parcelas }\end{array}$ & $\begin{array}{l}\text { Extensión } \\
\text { (f) }\end{array}$ & $\begin{array}{l}\text { Producc. } \\
\text { neta }\end{array}$ & $\begin{array}{l}\text { Producc. } \\
\text { bruta (a) }\end{array}$ & $\underset{\mathrm{H} / \mathrm{Ha}}{\text { Rendimis. }}$ & $\begin{array}{l}\text { Producc. } \\
\text { bruta (b) }\end{array}$ & $\begin{array}{c}\text { Rendimis. } \\
\mathrm{H} / \mathrm{Ha}\end{array}$ \\
\hline 1. ${ }^{1 / 2}$ S. XVIII. & 18 & 52,75 & 65,67 & 98,01 & 41,32 & 131,34 & 55,42 \\
\hline 1750-69. & 51 & 103,25 & 133,64 & 199,45 & 43 & 267,28 & 57,62 \\
\hline $1770-89$. & 76 & 106,97 & 147,31 & 219,87 & 45,75 & 294,62 & 61,31 \\
\hline 1790-1809. & 87 & 146,53 & 235,48 & 351,46 & 53,38 & 470,96 & 71,54 \\
\hline $1810-29$. & 42 & 76,17 & 110,81 & 165,38 & 48,63 & 221,62 & 64,76 \\
\hline $1830-49$. & 26 & 77,96 & 89,13 & 133,04 & 38,01 & 178,27 & 50,89 \\
\hline
\end{tabular}

TOTALES ..... $300 \quad 563,63 \quad(35,45$ Has. $)$

Creemos poder retener algunas consideaciones importantes:

1) Que el nivel de los rendimientos viticolas gallegos, en condiciones normales, es altamente productivo. Podríamos retener como cifras modélicas unas medias que oscilarian entre 45 y $60 \mathrm{HI} / \mathrm{Ha}$., según los cálculos seguidos en la elaboración de la tabla. Esto situaría a estos viñedos entre los más copiosos de la Europa de su tiempo(62).

2) Que no se percibe un ascenso definitivo y contundente de los rendimientos como en el caso de los cereales. En realidad, al final de la serie volvemos a encontrar valores similares a los de partida. La elevación progresiva que se vislumbra en la segunda mitad del siglo XVIII, en agudo contraste con el paralelo movimiento cerealero, pudiera venir explicada por razones climáticas, es decir sucesión de veranos cálidos que determinan una sobreabundancia de cosechas como muy bien ha sido probado para el caso francés ${ }^{(63)}$. No podemos afirmar un avance de los rendimientos vitícolas durante la fase estudiada. Al parecer, la crisis vitícola de mediados del siglo $X \mid X(64)$, ya viene precedida por un periodo de rendimientos decrecientes que se remontaría de una manera aproximada a 1810.

\section{III) OTROS RENDIMIENTOS AGRICOLAS}

Queremos terminar este trabajo con un acercamiento a otras dedicaciones más minoritarias, pero que por su papel en el equilibrio de las economías campesinas nos merecen su debida atención. Nos referimos a los prados/herbales, a las zonas de arbolado y a los numerosos tojales incluidos en nuestros patrimonios. Hemos considerado para las tres variables los rendimientos netos que tales dedicaciones ofrecen a sus patrimonialistas(65). También hemos buscado la relación entre el movimiento de estas especies y el de los precios de los cereales, en concreto el maíz(66).

a) Rendimientos del prado/herbal (en reales/ferrado). Base $100=1750-176967$ ): 
Rentabilid. Media por

Indice

Indice precios Parcelas (f)

neta (rs.) ferrado del maiz

\begin{tabular}{lcccccc}
$1 .{ }^{\mathrm{a}} 1 / 2$ s. XVIII . . & 15 & 52 & 576 & 11,08 & 70,06 & 62,8 \\
$1750-69 \ldots \ldots \ldots$ & 21 & 64,4 & 1.011 & 15,70 & 100 & 100 \\
$1770-89 \ldots \ldots$ & 26 & 57,95 & 1.097 & 18,93 & 120,6 & 109,1 \\
$1790-1809 \ldots \ldots$ & 25 & 82,8 & 3.043 & 37,23 & 237,13 & 185 \\
$1810-29 \ldots \ldots$ & 47 & 108,59 & 3.834 & 35,31 & 224,9 & 209 \\
$1830-49 \ldots \ldots$ & 27 & 116,6 & $2.795,5$ & 23,99 & 152,8 & 123,7 \\
\hline
\end{tabular}

TOTALES $\ldots . . \quad 161 \quad 482,34 \quad(30,34$ Has. $)$

b) Rendimientos de las zonas de arbolado (mismas bases)

\begin{tabular}{ccccccc}
$1 .{ }^{\mathrm{a}} 1 / 2$ s. XVIII . & - & - & - & - & - & - \\
$1750-69 \ldots \ldots$ & 21 & 80 & 741,5 & 9,27 & 100 & 100 \\
$1770-89 \ldots \ldots$ & 27 & 147,8 & 1.357 & 9,18 & 99 & 109,1 \\
$1790-1809 \ldots \ldots$ & 44 & 113,8 & 2.694 & 23,7 & 255,7 & 185 \\
$1810-29 \ldots \ldots$ & 35 & 93,8 & $1.654,5$ & 17,6 & 189,9 & 209 \\
$1830-49 \ldots \ldots$ & 30 & 138,98 & $2.132,5$ & 15,34 & 165,4 & 123,7 \\
\hline
\end{tabular}

TOTALES $\ldots . .157 \quad 574,38 \quad(36,13$ Has. $)$

c) Rendimientos del tojal/monte (mismas bases)

\begin{tabular}{lrlllll}
$1 .{ }^{a} 1 / 2$ s. XVIII . . & 9 & 51,5 & \multicolumn{1}{c}{233} & 4,52 & 93,8 & 62,8 \\
$1750-69 \ldots \ldots$ & 49 & 342,5 & $1.650,5$ & 4,82 & 100 & 100 \\
$1770-89 \ldots \ldots$ & 51 & 308,5 & 1.696 & 5,50 & 114,1 & 109,1 \\
$1790-1809 \ldots \ldots$ & 63 & 399,25 & 3.132 & 7,84 & 162,7 & 185 \\
$1810-29 \ldots \ldots$ & 102 & 455,5 & 3.847 & 8,45 & 175,3 & 209 \\
$1830-49 \ldots \ldots$ & 38 & 265,05 & 1.639 & 6,18 & 128,2 & 123,7 \\
\hline
\end{tabular}

TOTALES $\ldots . .312 \quad 1.822,3 \quad(114,62$ Has. $)$

Consideramos que la lectura de estas tablas(68) traduce apreciaciones de sumo interés. Una visión general nos indicaría que los precios cerealeros no comandan el movimiento alcista, a pesar de que la elevación de éstos es especialmente vigorosa en el caso gallego69). Las variables aquí 
manejadas responden de una forma concorde, sólo que superando con harta frecuencia el movimiento alcista de aquéllos.

Queremos destacar la especial elevación de los rendimientos pratenses. Si consideramos que esta valoración traduce la elevación progresiva del precio de la hierba(70), nos parece que esto refleja de una manera contundente los efectos de una creciente demanda sobre un producto que, por el doble efecto de la intensificación y de la estabulación, se ha vuelto imprescindible para el mantenimiento del equilibrio de las explotaciones agrarias. Esto nos explicaría el por qué los precios de la hierba y la valoración de los prados/herbales marchan casi siempre a la cabeza y nunca se sitúan por debajo de sus homónimos cerealeros. Pudiéramos afirmar que la alimentación del ganado se ha vuelto tan importante como la del propio hombre y ello a pesar de la fuerte presión demográfica existente. Sería en este contexto de una demanda tan marcada donde habria que situar la aparición de nuestros prados artificiales, creemos que confirmados por nuestros patrimonios(71), asi como las incesantes llamadas de la publicistica de esta época para su necesaria expansionn(72).Aunque se ha mitigado el alcance de tales praderias artificiales para estas fechas(73), lo cierto es que el tema merecería una mayor profundización. Sin duda, hay indicios de que, una vez más, las zonas litorales marchan avanzadas(74) y nada nos extrañaría que su ejemplo ganase paulatinamente las tierras del interior. ¿No estaremos ante una nueva respuesta espontánea campesina que es seguida a remolque por la élite culta? ¿Acaso no había sucedido ya con la aclimatación de la respuesta intensiva y con la captación del maíz?.

El vivo movimiento alcista de las diferentes dedicaciones arbóreas convendría retenerse también. Apréciese cómo no sólo resiste bien el alza de los precios cerealeros, sino que desde 1790 casi siempre camina por encima, a veces con notoria ventaja. Si el apartado anterior trasluce el problema de la perfección progresiva de la agricultura intensiva, esta otra variable nos está indicando que esta salida no ha sido, en modo alguno, la única. La presión demográfica encuentra también su respuesta en la extensión de los cultivos de la que con insistente frecuencia hablan los contemporáneos(75). Las roturaciones, haciendo retroceder las plantaciones de árboles, provocarían su escasez y la consecuente elevación espectacular del precio de la madera(76). ¿Es asimismo este cuadro de demanda creciente el que hace posible la expansión creciente del pino, conocido desde hacía más de un siglo, pero no generalizado hasta después de mediados del siglo XIX?77).

En cuanto al movimiento de la valoración de la producción de tojar, indicador indirecto de la intensificación, aunque no alcance la altura de las variables ya analizadas, es claro que sostiene muy bien el avance de los precios cerealeros; incluso le supera durante la mayor parte del siglo XVIII y al final del período estudiado. Parece evidente que las exigencias de una 
GRAFICO III: CONTRASTE EVOLUTIVO ENTRE LOS PRECIOS CEREALEROS Y ESTIMACION DE LAS ZONAS DE DEDICACION COMPLEMENTARIA (BASE $100=1750-69$ )

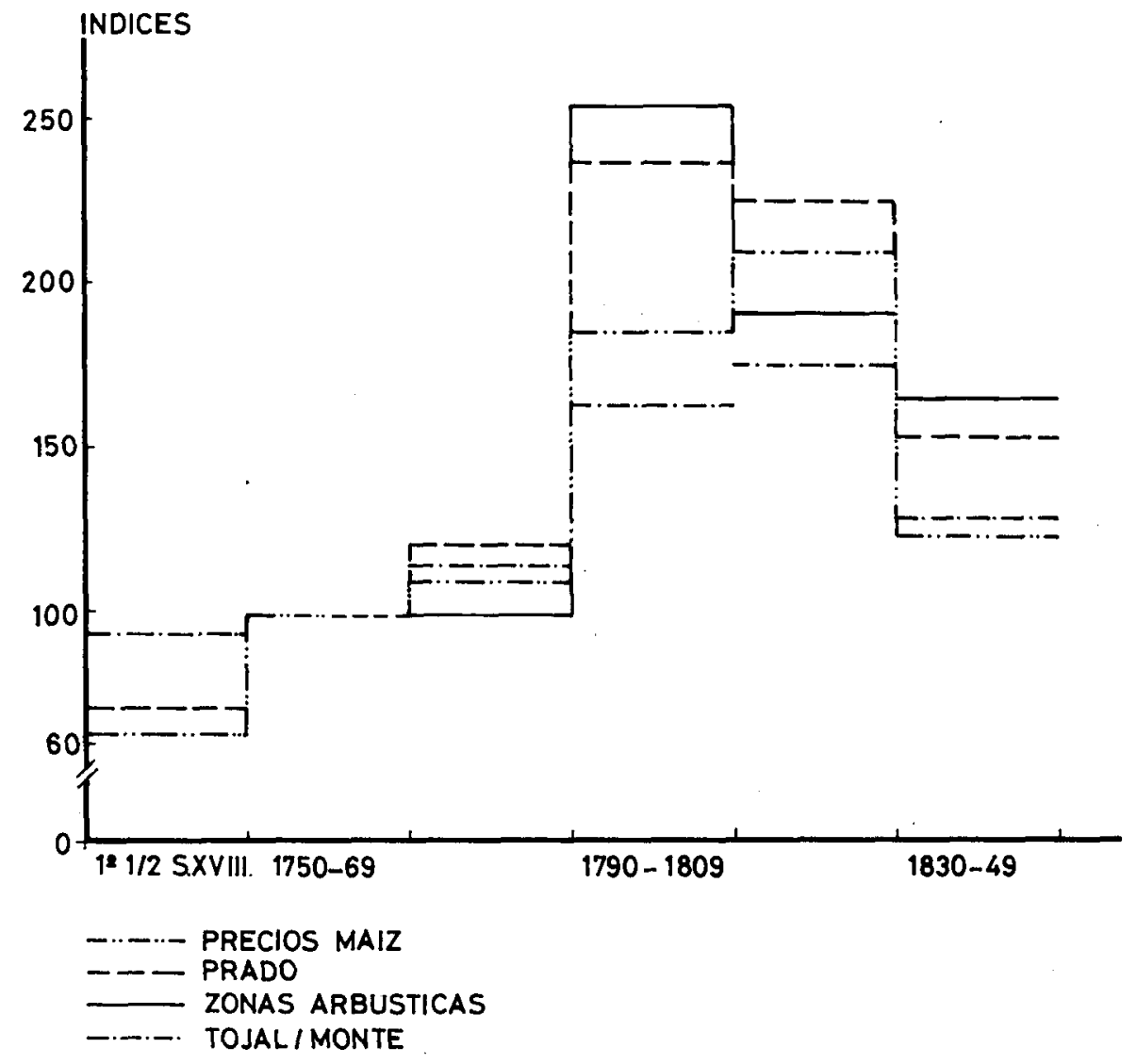


agricultura intensiva y los avances roturadores han potenciado la importancia de este elemento complementario, que se ha vuelto cada vez más preciso y estimado(78). El análisis comparativo de la composición interna de los patrimonios en las fechas extremas de este estudio, creemos que nos ofrece datos de interés y confirma las anteriores apreciaciones. Veamos:

A) Periodo 1740-69

AREAS CEOGRAFICAS

$\begin{array}{ccccc}\text { N. } & \begin{array}{c}\text { a) } \bar{x} \text { tierras } \\ \text { labor, prado, } \\ \text { viñedo } y \text { huerta } \\ \text { (ferrados) }\end{array} & \begin{array}{c}\text { b) } \bar{x} \text { parcelas } \\ \text { mixtas, tojal } y \\ \text { arbolado }\end{array} & \begin{array}{c}\bar{x} \\ \text { Total }\end{array} & \begin{array}{c}\% \text { de b) } \\ \text { sobre } \\ \text { Patrs. }\end{array}\end{array}$

\begin{tabular}{lccccc}
\hline Litoral ........... & 23 & 29,7 & 17,8 & 47,5 & 37,5 \\
Depresión Meridiana. . & 16 & 39,1 & 22 & 61 & 36 \\
Transición e Interior . & 16 & 60,1 & 4,5 & 64,7 & 7,5
\end{tabular}

B) Período $1820-49$

Litoral ........... 23

Depresión Meridiana . 35

Transición e Interior . $\quad 21$
$23 \quad 19,56$

18,50

39,37
11,24

16,81

26,27
30,8

35,31

36,5

47,6

$65,84 \quad 40$

Creemos poder apreciar aspectos importantes:

a) Que existe siempre un notorio equilibrio entre las zonas cultivadas y las áreas complementarias de tojal/monte, de donde ha de salir el esquilmo necesario para esta agricultura intensiva. Esta es una de las claves fundamentales del sostenimiento de este hábil complejo agrario(79). En este sentido, nuestros patrimonios equivalen a auténticas explotaciones completas.

b) Podemos apreciar el enorme ascenso del tojal/monte en las zonas de los valles medios-altos. Parece evidente que estas demarcaciones, con notorio retraso con relación a las demás zonas, han entrevisto la necesidad imperiosa de contar con estas parcelas complementarias en sus explotaciones particulares. Esta atención creciente sobre el tojal nos explicaría el avance de los rendimientos y el triunfo de una agricultura intensiva armónica que habría ganado también estas comarcas interiores de la Galicia occidental a lo largo de la fase estudiada(80). Sin duda, la atención al abonado no era nueva en estas tierras, pero habría que suponer que esta práctica se habría acentuado a partir de una mayor estabulación ganadera. 
c) Que el avance combinado de los precios y de la productividad de nuestros agros han permitido reducir el monte necesario de tierras exigidos a estos candidatos a ordenes mayores, si tenemos en cuenta que la cóngrua requerida ha permanecido estable. Crremos que es una prueba más de un ascenso real de los rendimientos en la totalidad de las demarcaciones estudiadas.

\section{CONCLUSION}

A la hora de establecer un pequeño balance global del presente trabajo, convendría llamar la atención sobre el hecho de que nuestras conclusiones nos merecen más crédito en el conjunto de los datos de rendimientos obtenidos, que en el de las hipótesis interpretativas que los acompañan. Consideramos los riesgos que se derivan al intentar comprender una cultura agraria a través de una sola de sus variables, por muy importante que ésta sea. Debemos, pues, ser prudentes y tomar las consideraciones que siguen como una invitación a profundizar en las transformaciones agrarias de este primer siglo $\mathrm{XIX}$, hasta ahora poco estudiado.

1) La afirmación más clara que hemos establecido sería que los rendimientos cerealeros habrían ascendido entre 1740 y 1850 en unos porcentajes situables entre el 39 y el $44 \%$ según las demarcaciones; sea una cifra media global aproximativa del $40 \%$. De un nivel cercano a $7 \times 1$ en las zonas litorales, de $6 \times 1$ en la depresión meridiana y de $5 \times 1$ en las zonas medias-altas, se pasaria a otro 10,8 y $7 \times 1$ respectivamente, ganando todas las zonas de 2 a 3 puntos en la escala de estos rendimientos por superficie. Si se prefiere, podríamos retener 20,18 y $16 \mathrm{HI} / \mathrm{Ha}$. como punto de partida y 28,26 y $22 \mathrm{HI} / \mathrm{Ha}$. como punto de llegada. Esta elevación es tanto más significativa, si tenemos en cuenta el alto nivel del que se parte, a la luz de la bibliografia comparativa disponible.

2) El análisis temporal y la distribución de los intervalos de rendimientos parecen probar que, aunque las diferencias de virtuosismo agrario se mantienen, no dejó de producirse una notable aproximación de comportamiento entre las zonas estudiadas, quizás debida al perfeccionamiento de las agriculturas interiores por un paulatino traspaso de las prácticas de cultivo más evolucionadas de la costa. La modernización agraria, expresada en los rendimientos alcanzados, tal vez haya seguido el curso de las vias fluviales, desde la desembocadura a sus cursos altos. Lo que sí parece evidente es que las demarcaciones analizadas van alcanzando cotas de rendimientoscerealeros con 20030 años de retraso con relación al área inmediata más occidental. Dicho de otra manera: por encima de los $300 \mathrm{~m}$. de altitud-cursos fluviales medios y altos-se aprecia un retraso de medio siglo con relación a las dinámicas demarcaciones costeras. Los años 
setenta para éstas últimas, los años noventa para las fértiles tierras de los valles inferiores y los años veinte del siglo XIX para las montañosas localidades interiores, cierran un notable período de estancamiento en los rendimientos agrícolas e inician unas paralelas fases de alza que los llevarian a las cotas antes mencionadas.

3) A los altos rendimientos cerealeros, visibles en el maíz de una manera muy especial-la especie más eficaz y mejor cultivada-se corresponden unos rendimientos vitícolas no menos espectaculares. Las vides gallegas occidentales podían suministrar de 45 a $60 \mathrm{hl} / \mathrm{Ha}$. en cosechas medias normales. No obstante, al contrario de sus homónimos cerealeros, no hemos apreciado una elevación sostenida de sus rendimientos. Los primorosos cuidados a que son sometidas estas pequeñas parcelas hacia mediados del siglo XVII|(81), seguramente permitieron establecer unos baremos difíciles de superar. Tan sólo en las excepcionales fases climáticas, como sucedió en la segunda mitad del siglo XVIII, pudiendo lograrse copiosas cosechas que elevaron la productividad y cooperaron a la baja de los precios viticolas. Sin embargo, no fue definitiva y hacia mediados del siglo XIX volvemos a toparnos con unos rendimientos que ya se habian logrado un siglo antes.

4) La alta estimación de las áreas de complemento ganaderoprados/herbales_o agrícola-tojal/monte-resulta muy significativa. A manera de hipotesis razonable, creemos que ello confirma la doble salida ensayada por una demografía ascendente durante el período, antes de la riada migratoria de épocas posteriores:

-De un lado, la respuesta intensiva manifestada en la elevación de los rendimientos, en la introducción de las praderias y pastos artificiales - lamentablemente desconocemos su alcance-, en la valoración creciente de los prados por la estabulación ganadera y en la manifiesta atención prestada a las parcelas de tojal. Es el triunfo de un virtuosismo progresivo propio de una agricultura equilibrada y hábil que habria ganado, al menos, todo el marco occidental gallego situado al sur del Tambre.

-De otro, tendríamos la respuesta extensiva, destacada también por los contemporáneos, y que para nosotros queda reflejada en las altas cotizaciones de la madera, quizás por efecto de las talas excesivas e indiscriminadas, y en la acaparación progresiva de tojales comunales para convertirlos en privados.

Quizás a medida que nos acercamos a la costa y a las más altas densidades prime la primera respuesta, si tenemos en cuenta que la posibilidad de ganar nuevas tierras sería reducida(82); tal vez, a medida que nos adentramos en el interior gallego y las tierras disponibles son mayores por la menor presión demográfica, predomine la segunda salida. En todo caso, ambas parecen irrebatibles en este contexto histórico. 


\section{A P E N D I C E}

\section{TABLA I}

LITORAL: Evolución decenal de los rendimientos cerealeros

\begin{tabular}{|c|c|c|c|c|}
\hline$A \tilde{N} O S$ & $\begin{array}{c}\text { N. }{ }^{\circ} \\
\text { Parcelas }\end{array}$ & $\begin{array}{l}\text { Extensión } \\
\text { (f) }\end{array}$ & $\begin{array}{l}\text { Producción } \\
\text { (f) }\end{array}$ & Rendimientos \\
\hline 1. ${ }^{a} 1 / 2$ s. XVIII ........ & 61 & 173,75 & 1.151 & 6,62 \\
\hline $1750-59 \ldots \ldots \ldots \ldots$ & 27 & 87,75 & 600 & 6,84 \\
\hline $1760-69 \ldots \ldots \ldots \ldots$ & 49 & 137,75 & 911,5 & 6,62 \\
\hline $1770-79 \ldots \ldots \ldots \ldots$ & 40 & 104,75 & 758 & 7,24 \\
\hline $1780-89 \ldots \ldots \ldots \ldots$ & 25 & 54,5 & 395 & 7,25 \\
\hline $1790-99 \ldots$ & 85 & 171,25 & $1.315,5$ & 7,68 \\
\hline $1800-09 \ldots \ldots \ldots \ldots$ & 66 & 141 & 1.043 & 7,40 \\
\hline $1810-19 \ldots \ldots \ldots \ldots$ & 63 & 115 & 964 & 8,38 \\
\hline $1820-29 \ldots \ldots \ldots \ldots \ldots$ & 60 & 179,75 & $1.454,5$ & 8,09 \\
\hline $1830-39 \ldots \ldots \ldots \ldots$ & 51 & 134 & 1.352 & 10,09 \\
\hline $1840-49 \ldots \ldots \ldots \ldots$ & 15 & 61,75 & 591 & 9,57 \\
\hline
\end{tabular}

TABLA II

DEPRESION MERIDIANA: Evolución decenal de los rendimientos cerealeros

\begin{tabular}{|c|c|c|c|c|}
\hline$A \tilde{N} O S$ & $\begin{array}{c}\text { N.o } \\
\text { Parcelas }\end{array}$ & $\begin{array}{l}\text { Extensión } \\
\text { (f) }\end{array}$ & $\begin{array}{l}\text { Producción } \\
\text { (f) }\end{array}$ & Rendimientos \\
\hline 1. a $1 / 2$ s. XVIII ......... & 46 & 407,5 & 2.485 & 6,10 \\
\hline $1750-59 \ldots \ldots \ldots \ldots$ & 67 & 205,25 & 1.348 & 6,57 \\
\hline $1760-69 \ldots \ldots \ldots \ldots$ & 76 & 217,75 & $1.306,5$ & 6,00 \\
\hline $1770-79 \ldots \ldots \ldots \ldots$ & 77 & 313,5 & 1.681 & 5,36 \\
\hline $1780-89 \ldots \ldots \ldots \ldots$ & 109 & 254 & $1.651,5$ & 6,50 \\
\hline $1790-99 \ldots \ldots \ldots \ldots$ & 72 & 145,5 & 985,5 & 6,77 \\
\hline $1800-09$ & 83 & 180 & 1.372 & 7,62 \\
\hline $1810-19 \ldots \ldots \ldots \ldots \ldots$ & 126 & 239,25 & 1.953 & 8,16 \\
\hline $1820-29 \ldots \ldots \ldots \ldots$ & 71 & 185 & 1.449 & 7,83 \\
\hline $1830-39 \ldots \ldots \ldots \ldots$ & 82 & 241 & $1.921,5$ & 7,97 \\
\hline $1840-49 \ldots \ldots \ldots \ldots$ & 68 & 100 & $1.032,5$ & 10,32 \\
\hline
\end{tabular}


TABLA III

\section{TRANSICION A INTERIOR E INTERIOR}

Evolución decenal de los rendimientos cerealeros

\begin{tabular}{|c|c|c|c|c|}
\hline$A \tilde{N} O S$ & $\begin{array}{c}\text { N. }{ }^{\circ} \\
\text { Parcelas }\end{array}$ & $\begin{array}{l}\text { Extensión } \\
\text { (f) }\end{array}$ & $\begin{array}{l}\text { Producción } \\
\text { (f) }\end{array}$ & Rendimientos \\
\hline 1. a $1 / 2$ s. XVIII & 78 & 745,5 & 4.269 & 5,73 \\
\hline $1750-59 \ldots$. & 80 & 349,5 & 1.727 & 4,94 \\
\hline$\ldots \ldots \ldots \ldots$ & - & - & - & - \\
\hline $1770-79$. & 44 & 193 & 995 & 4,95 \\
\hline $1780-89 \ldots \ldots \ldots$ & 46 & 278 & 1.473 & 5,30 \\
\hline $1790-99$ & 43 & 157,5 & 1.094 & 6,95 \\
\hline $1800-09$ & 46 & 211 & 1.439 & 6,82 \\
\hline $1810-19$ & 62 & 152 & 856 & 5,63 \\
\hline $1820-29$. & 36 & 148 & 1.051 & 7,10 \\
\hline $1830-39 \ldots \ldots \ldots \ldots \ldots$ & 93 & 233 & $1.882,5$ & 8,08 \\
\hline $1840-49 \ldots \ldots \ldots \ldots$ & 73 & 412 & 3.219 & 7,81 \\
\hline
\end{tabular}




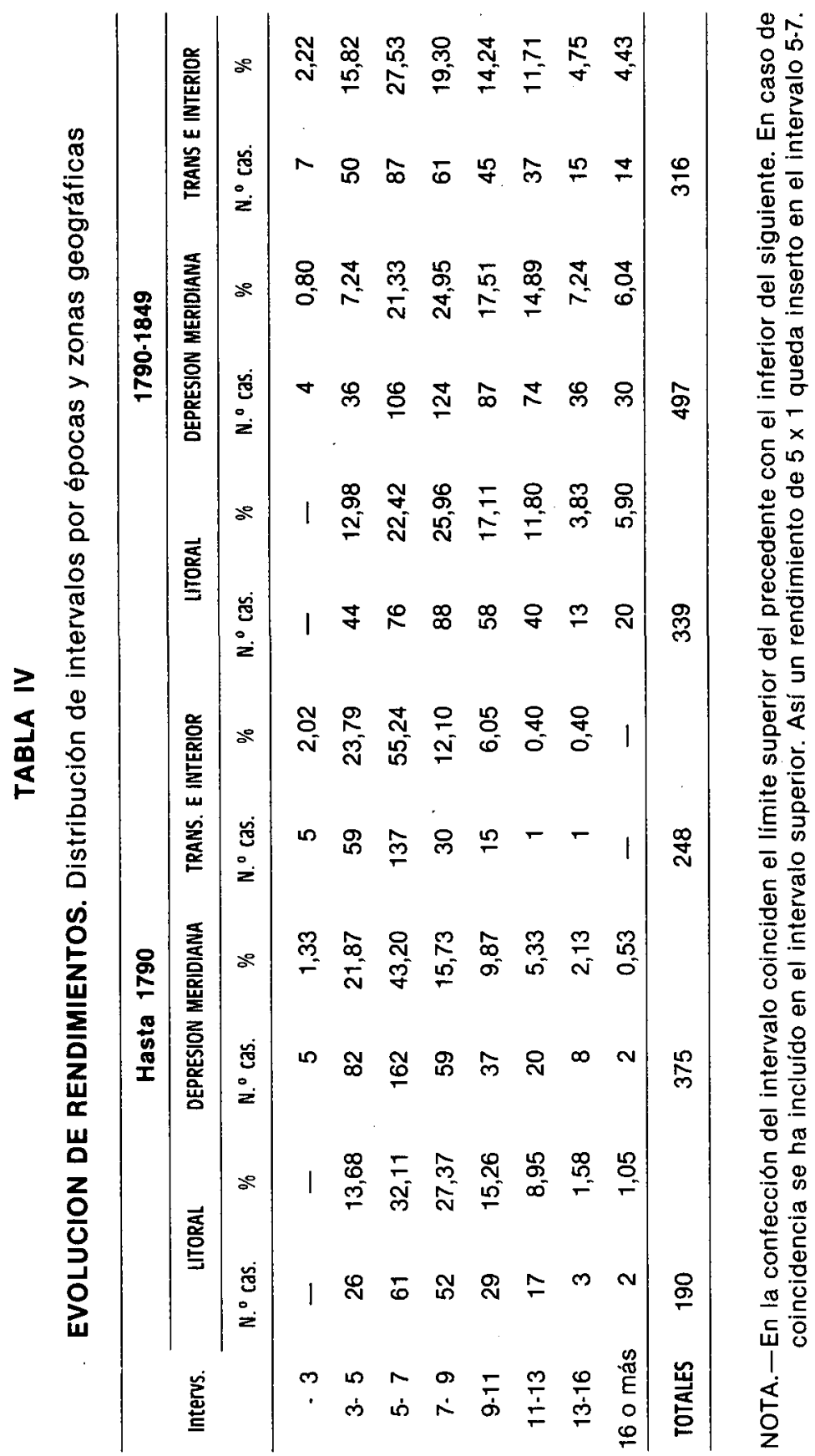




\section{TABLA V}

\section{CONJUNTO DE LAS TRES AREAS GEOGRAFICAS}

Evolución de la valoración del tojal/monte por decenios

\begin{tabular}{|c|c|c|c|c|}
\hline$A \tilde{N} O S$ & $\begin{array}{c}\text { N. }{ }^{\mathbf{o}} \\
\text { Parcelas }\end{array}$ & $\begin{array}{l}\text { Extensión } \\
\text { (f) }\end{array}$ & $\begin{array}{c}\text { Estimación } \\
\text { liquida } \\
\text { (en reales) }\end{array}$ & $\begin{array}{l}\text { Rendimiento } \\
\text { (rs. por f.) }\end{array}$ \\
\hline 1. a $1 / 2$ s. XVIII .......... & 9 & 51,5 & 233 & 4,52 \\
\hline $1750-59 \ldots \ldots . \ldots$ & 19 & 123,5 & 641 & 5,19 \\
\hline $1760-69 \ldots \ldots \ldots$ & 30 & 219 & $1.009,5$ & 4,61 \\
\hline $1770-79 \ldots \ldots \ldots$ & 21 & 143,1 & 616 & 4,30 \\
\hline $1780-89 \ldots \ldots . . . \ldots$ & 30 & 165,4 & 1.080 & 5,63 \\
\hline $1790-99 \ldots \ldots$ & 32 & 232,5 & 1.480 & 6,37 \\
\hline $1800-09 \ldots \ldots \ldots$ & 31 & 166,75 & 1.652 & 9,91 \\
\hline $1810-19$ & 61 & 281,5 & 2.305 & 8,19 \\
\hline $1820-29$ & 41 & 174 & 1.542 & 8,86 \\
\hline $1830-39 \ldots \ldots \ldots$ & 25 & 116,3 & 875 & 7,5 \\
\hline $1840-49 \ldots \ldots \ldots$ & 13 & 148,75 & 764 & 5,14 \\
\hline
\end{tabular}


(1) Esta encuesta sobre rendimientos agricolas a partir de patrimonios eclesiásticos arranca de nuestra Tesis Doctoral. Vid. PEREZ GARCIA, J. M. Un modelo de sociedad rural de Antiguo Régimen en la Galicia costera. La Península del Salnés. Univ. Santiago, 1979, pp. 195-97.

(2) Vid. nuestro trabajo: «La agricultura gallega de mediados del siglo XVIII a través de sus rendimientos: una respuesta alternativa».

(3) Ha sido necesaria una amplia encuesta en los siguientes fondos documentales: Archjvo diocesano de Tuy (A.D.T.), Hospital de Pobres, en sus secciones de protocolos (15 patrimonios de los escribanos González Manzanares y González del Pino) y de patrimonios (22 escrituras, legajos 1 a 4); Archivo Capitular de Santiago (A.C.S.) en catalogación (10 escrituras); Archivo Diocesano de Santiago (A.D.S.) en sus secciones de patrimonios (165 escrituras patrimoniales para las que ha sido preciso revisar en su totalidad las carpetas de patrimonios $n .{ }^{\circ} 1,2,3,4,5,6$, $7,8,9,28,29,38,39,52,53,54,55,56,75,78,80,81,82,83,86,98,101,102,104,105,109,110,113$, $114,115,119$ y 120 , y Capellanías, (9 casos en los legajos 382, 383, 385 y 387); Archivo Histórico y Universitario de Santiago (A.H.U.S.) en su sección de protocolos (2 casos en los protocolos n. ${ }^{\circ}$ 3.938 y 3.941 ). Por último, el Archivo Histórico Provincial de Pontevedra (A.H.P.P.) en la sección de protocolos (83 casos de los escribanos y notarios siguientes: D. Rolán, legs. G 53 B, G 53 C y G 54 B; A. Chan y Caldas G 127B, G 128 B y G 160; J. A. Fuente, G 280; B. Oliver y Paz, G 287 y G 288; A. Correa, G 322; J. Ortega, G 326; Peña y Aballe, G 327 y G 328; F. J. Varela Patiño, G 365 y G 367; Suárez Cobián, G 519; Vilavedra y Conde, G 483; G. Viqueira, G 507; García Villamarín, G 519; Estévez de Prado, G 523; Vilanova Gil, G 524; Porto Mariño, G 525; Gimeno, G 528 y G 529; Varela Patiño, G 567; Pardo Andrade, G 571; Alvarez G 572 y G 573; Peña y Oña G 575, G 576 y G 578 y, por último, Miranda, G 1.436. Hemos retenido tan sólo los legajos y carpetas de los que hemos obtenido información válida. Debemos expresar nuestro agradecimiento a los señores archiveros Domato Búa, Díaz, Gómez Sobrino y López Gómez por las facilidades encontradas en la consulta de los fondos por ellos custodiados. Invitamos desde estas líneas a continuar nuestra encuesta gallega en las restantes diócesis no visitadas por nosotros.

(4) Ello obedece al hecho de que para algunas zonas, y de una manera sistemática, no se ofrecen producciones sino las rentas que producirían tales parcelas en caso de que fueran aforadas. Esta era la salida normal, toda vez que a los eclesiásticos les estaba vedado la dedicación a las labores agrícolas.

(5) Creemos que el número de parcelas sometidas a estudio es suficiente y garantiza la representatividad de nuestras medias.

(6) Reteniendo tan sólo los municipios con 3 o más patrimonios, esta área queda representada en esta muestra por los ayuntamientos de Rianxo, Porto do Son, Vilagarcla, Vilanova de Arousa, Gambados, Ribadumia, O Grove, Meaño y Marín. De estos 93 casos, 71 corresponderían a la Ría de Arosa, 9 a la de Noia, 7 a la de Vigo y 6 a la de Pontevedra. Vid. mapa de sondeo municipal donde se representan aquellos municipios para los que se dispone de dos patrimonios al menos.

(7) Comprende los municipios de Brión, Ames, Rois, Lousame, Santiago, Vedra, Valga, Caldas, Moraña, Barro, Cuntis, Portas, Meis, Pontevedra, Gondomar y Tui. Del total, 23 representan a la cuenca media del Tambre, 26 a la del Ulla, 47 a la del Umia, 10 a la del Lérez, 2 a la del Oitavén y 21 a la del Miño.

(8) Integrada por los municipios de O Pino, A Baña, Vila de Cruces, A Estrada, Forcarei, Cerdedo, Campo Lameiro, Cotobade y Ponte Caldelas. Corresponden a la cuenca alta del Tambe 10, a la del Ulla 29, a la del Lérez 25, a la del Oitavén 8 y a la del Miño 10.

(9) Y ello gracias a recurrir a los fondos de capellanías que han sido utilizados tan sólo para esta primera mitad del siglo XVIII. De aqui proceden 18 del total de 28 escrituras utilizadas en este periodo. Han sido controlados los datos de estos bienes de capellanias que son concordantes con los patrimoniales. La homogeneidad de la muestra queda así garantizada para sus comienzos.

(10) Gonzalo Anes en el I/I Conferencia Internacional de Historia Económica (C.I.H.E.), 
reducia las posibilidades de análisis de la productividad a estas fuentes. Vid ANES, G. «Production et productivité agricoles dans les deux Castilles de la fin du XVII ${ }^{\ominus}$ siècle à 1836 m. Munich, 1965, p. 87.

(11) Basta remontarse a sus primeras aportaciones (Vide SLICHER VAN BATH, B. H. "La productivité agricole. Les problèmes fondamentaux de la société pré-industrielle en Europen. IIIC.I.H.E., Munich, 1965, p. 27). Este optimismo inicial se mitigó un poco en las obras posteriores del mismo autor: Historia agraria de Europa Occidental. 500-1850. Barcelona, 1974, pp. 212-214, y el "La agricultura en la evolución vital» inserta en Historia Económica de Europa de la Universidad de Cambridge. V. V, Madrid, 1981, pp. 102-105. En esta última señala una elevación de los rendimientos europeos desde 1750 cifrada entre el $10 \%$ del Oeste europeo y el $25-30 \%$ del Este.

(12) El autor situa en la segunda mitad del siglo XVIII una intensividad creciente en la agricultura alemana. Vid. ABEL, W. Crises agraires en Europe (XI//*-XX` siècle. París, 1973, pp. 28689.

(13) El representante más significativo de esta línea tal vez sea MORINEAU, M. Les faux semblents d'un demarrage economique: agriculture et démographie en France au XVIII' siècle. Paris, 1970, pp. 24 y ss. Este autor nos habla de una larga estabilidad de los rendimientos franceses que aún carecerian de brillantez en 1840. En un artículo posterior titulado aRevolution agricole, revolution alimentaire, revolution démographiquew. Annales de Démographie Historique, 1974 , pp. 345 y ss., sigue defendiendo esta inmovilidad de los rendimientos cerealeros franceses, aunque reconoce avances aislados que no invalidan su tesis central. También GOY, J. "Les rendements du blé au Pays d'Arles XVII-XVIII' siècles" en Fluctuations du produit de la díme. Paris, 1972, pp. 245-254, constata una degradación progresiva de los rendimientos languedocianos y provenzales.

(14) Sin embargo, para Le Roy Ladurie los rendimientos del Languedoc habria pasado de 4 $\times 1$ a $6 \times 1$ a lo largo del siglo XVIII. Vid. LE ROY LADURIE, E. "Les rendements du blé en Languedoc». III C.I.H.E., Munich, 1965, pp. 77-82. Su obra capital Les paysans de Languedoc. Paris, 1966, pp. 639-40 y 652-54, rezuma optimismo de forma que su famoso drama maltusiano se habria roto en el siglo XVIII dejando atrás un ciclo agrario concluído hacia 1715-20. Los rendimientos de 3 a 4,5 $\times 1$ del viejo ciclo se convierten en 5 a $8 \times 1$ bajo Luis XVI y fechas posteriores. Este optimismo del autor ha perdido hoy muchos enteros. Destaquemos, por ejemplo, el cuadro estabilizador que nos ofrece el autor en este siglo XVIII para el conjunto francés, del que sólo cabe hacer excepción con el extremo Norte de Francia en donde se pasa de unos 23 a $26 \mathrm{Hi} / \mathrm{Ha}$. durante el periodo que va de 1715 a 1780 . Vid. LE ROY LADURIE, E. "De la crise ultime à la vrai croissance (1660-1789)" en la Histoire de la France rurale dirigida por Duby. Paris, 1975, p. 416.

(15) Zytrowicz ha visto para Polonia en su fase III, sea a mediados del siglo XVIII, como los rendimientos inferiores a $2 \times 1$ desaparecen en tanto crecen los de 4 a $7 \times 1$. Vid. ZYTROWICZ, $L$. "Production et productivité de l'economie agricole en Pologne aux XV|⿱一𫝀口-XVIII' siècles". III C.I.H.E., Munich, 1965, p. 160. Por su parte MAKKAl, L. "Production et productivité agricoles en Hongrie à l'ére du feudalisme tardien. III C.I.H.E. Munich, 1965, p. 176, refiere para el caso húngaro como entre 1780 y 1850 los considerados como buenos rendimientos pasan de $5 \times 1$ a $6-8 \times 1$.

(16) Para Anes no hubo ni intensificación, ni aumento de los rendimientos en el siglo XVIII. Vid. ANES, G. Las crisis agrarias en la España moderna. Madrid, 1970, pp. 194-96.

(17) Asi para GARCIA SANZ, A. Desarrollo y crisis del Antiguo Régimen en Castilla la Vieja. Economia y sociedad en tierras de Segovia. Madrid, 1977, pp. 156-57, no hubo cambios llamativos en los rendimientos castellanos del siglo XVIII.

(18) Podriamos citar a JUAN VIDAL, J. "Técnicas, rendimientos y productividad agrícola en la Mallorca Moderna», en ANES, G. y otros. La Economia Agraria en la Historia de España. Madrid, 1979, p. 52. El autor afirma que los rendimientos mallorquines no aumentaron a lo largo del siglo XVIII.

(19) PONSOT, P., en sus trabajos publicados como "En Andalousie Occidentale: les fluctuations de la production du blé sous l'Ancien Régimen en Les Fluctuations..., op. cit., p. 408 y en "Rendement des cereales et rente fonciere dans la Campiña de Cordove au debut du XVII et au debut du XIX". Anexos Hispania 7, pp. 480-81, destaca en ambos casos el avance de los rendi- 
mientos en los cortijos andaluces. Por su parte, BRUMONT, F. «Comtes d'exploitations et histoire economique: l'exemple de la "Granjan de Quintanajuar (1625-1835)". Melanges de la Casa Velázquez. T. XVI, 1979, p. 398, encuentra una elevación de los rendimientos del $23 \%$ en la segunda mitad del siglo XVIII con relación a la primera. Claro que ambos casos reproducen modelos agricolas extensivos de bajos rendimientos, siempre inferiores a $5 \times 1$.

(20) Asi ORTEGA VALCARCEL, J. La transformación de un espacio rural. Las montañas de Burgos. Univ. Valladolid, 1974, pp. 172-73, encuentra en el siglo XVIII y comienzos del XIX unos rendimientos de 6 a $8 \times 1$, muy superiores a los del siglo XVI, cifrados en $3,5 \times 1$, para su zona burgalesa.

(21) Vilar registra un indudable aumento en los rendimientos catalanes dieciochescos, tanto en las tierras de secano como en las que habian sido irrigadas en época reciente. Vid. discusión que sigue a la comunicación de G. Anes en el III C.I.H.E. Munich, 1965, p. 95.

(22) En la huerta valenciana parece haberse pasado de $13 \mathrm{HI} / \mathrm{Ha}$. registrados para la primera mitad del siglo XVIII a $20 \mathrm{HI} / \mathrm{Ha}$. en la segunda. Vid. BENITEZ SANCHEZ-BLANCO, R. «Producción y consumo en la huerta de Valencia en la primera mitad del siglo XVIII. El caso del monaste-

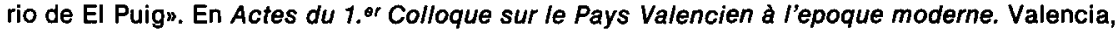
1980, p.' 260, y Apéndice p. 271.

(23) Véase GARCIA LOMBARDERO, J. La agricultura gallega y el estancamiento económico de Galicia en la España del Antiguo Régimen. Madrid, 1973, en donde en diversas ocasiones -ejemplo pp. 26-27 o 60-61 - se niega la intensificación de cultivos en Galicia. Más radical aún nos parece su posterior postura en aHacia una historia económica de las nacionalidades. Datos para el estudio de la estructura del poder económico del clero gallego en el siglo XVIII". Revista de Hacienda Pública Española, n. ${ }^{\circ} 38,1976$, pp. 100-107, en donde se afirma que el producto de la tierra en Galicia uera el más bajo de las veintidós provincias de Castilla y con una diferencia bastante considerable". Para una crítica de esto véase nuestro trabajo: "Algunas reflexiones en torno a la utilización de los resúmenes generales de la Unican. Cuadernos de Estudios Gallegos, T. XXXI, n. ${ }^{\circ}$ 93-95, pp. 156-160.

(24) El autor destaca los escasos cambios verificados en la agricultura gallega del siglo XIX, Vid. VILLARES PAZ, R. La propiedad agricola y las rentas de la tierra en la Galicia interior. Tesis de Doctorado. Inédita. Univ. Santiago, 1980. Más radicalizada nos parece su postura cuando abunda en el "carácter ruinoso" de la agricultura gallega y en el mantenimiento de la situación desde mediados del siglo XVIII a 1890 (Vid. VILLARES PAZ, R. y otros. Historia de Galicia. Alhambra, Madrid, 1980, pp. 248-249). La rotundidad de estas expresiones hay que entenderla en relación a una agricultura de cuño capitalista, no minifundista, afectada por las revoluciones quimica y tecnológica, en cualquier caso no anterior a mediados del siglo XIX. Sin embargo, inserta en el cuadro de las agriculturas europeas tradicionales vigentes hasta entonces, la agricultura gallega creemos que no debe ser juzgada de una forma tan peyorativa, sino todo lo contrario. También sería explicable tal postura por la excesiva generalización del modelo lucense al resto de la geografía galaica. Autores prestigiosos como Planeltas, Díaz de Rábago o Valenzuela Ozores ya comprendieron entonces perfectamente este retraso lucense, no extensible al resto de Galicia. Vid. por ejemplo PLANELLAS, J. Intervención en el Congreso Agrícola de 1964. Santiago, p. 154, que nos refiere la antigüedad del sistema de rotaciones en Galicia, en el cual se encuadrarian las $3 / 4$ partes de la misma, quedando una parte reducida en la que reinan los barbechos.

(25) El Prof. Eiras Roel ha llamado la atención en su magna encuesta diezmal sobre la gran capacidad dinámica de la agricultura gallega de casi triplicar la producción en las curvas mindonienses o más que duplicarla en las zonas litorales. Vid EIRAS ROEL, A. "Dîme et mouvement du produit agricole en Galice (1600-1837)". Coloquio Internacional sobre el Diezmo y el movimiento de la Producción agraria. Paris, 1977.

(26) Véase PEREZ GARCIA, J. M. Un modelo...., op. cit., p. 195 y ss. Entonces definimos esta indudable elevación, comprobada a través del uso de diversas fuentes alternativas, como "revolución de los rendimientos", quizás de manera enfática.

(27) El estudio sobre el Burón pone en claro que la intensificación ganó también las 
tierras anteriores. Vid. SAAVEDRA FERNANDEZ, P. Economia rural antigua en la meseta lucense. El Concejo de Burón. Univ. Santiago, 1979, pp. 45-46 y del mismo uA Galicia da Edade Moderna: 1480-1808n, en Historia de Galicia. Ed. Planeta, Barcelona, 1980, p. 36. También en PEDROUZO VIZCAINO, O. El arciprestazgo de Narla en el Antiguo Régimen: un estudio de Historia Rural. Tesis de Licenciatura, inédita. Univ. Santiago, 1981. Esta realidad viene confirmada por testimonios de época y asi D. Antonio Salgado lamentaba que desde fines del siglo XVIII muchas agras se hubieran reducido a cortinas. Vid. SALGADO, A. Notas de D. Antonio Salgado. 1858. Archivo Histórico Nacional, Clero, Códice 1.054 B. Damos las gracias a Ramón Villares por la cesión de estas notas manuscritas del autor.

(28) Bohuier no regatea amplios elogios al minifundio gallego como cuando lo califica de "uno de los más lógicos y acabados". Vid. BOUHIER, A. La Galice. Essai geographique d'analyse et d'interpretation d'un vieux complexe agraire. La Roche-sur-Yon, 1979, T. II, p. 1.197.

(29) Podríamos tomar de ejemplos a CASTRO BOLAÑO, J. M. Informe sobre el estado de los montes de la provincia de Lugo y los medios de proveer a su conservación. Lugo, 1850, pp. 47. También puede verse PARDO BAZAN, J. CONDE DE PALLARES. Memoria sobre la necesidad de establecer escuelas de Agricultura en Galicia. Madrid, 1862, pp. 46-47.

(30) Para SALGADO, A. Notas...., op. cit., cuando lamenta las excesivas roturaciones en las zonas litorales y de valles lo que ha llevado a sus labradores a estar "todavia más pobres que los montañeses" y por eso aparecen aquí "flacos, estenuados y desnudos". Véase, por el contrario, VALENZUELA OZORES, A. Memoria estadística sobre la provincia de Pontevedra y el Censo de 1860 . Pontevedra, 1862, p. 87, para quien la subdivisión de la propiedad no es sinónimo de agricultura atrasada pues siendo "más extremada en los valles que en las montañas; sin embargo, en éstas está el cultivo mucho más atrasado".

(31) Ya SOMOZA DE MONSORIU, F. Estorvos i remedios de la riqueza de Galicia. Santiago, 1775, T. I. p. 215 en pleno siglo XVIII destaca «la inteligencia profunda de los Naturales en la Agriculturan. Medio siglo más tarde GONZALEZ DE ZUÑIGA, C. Descripción económica de la provincia de Pontevedra. Pontevedra, 1834, p. 5, repite estos adjetivos.

(32) El propio COLMEIRO, M. Memoria sobre el medio más acertado de remediar los males inherentes a la extremada subdivisión de la propiedad territorial en Galicia. Santiago, 1843, $p$. 34 , no dado a exageraciones, señala que las tierras en Galicia no huelgan una sola semana pues "alzada una cosecha se prepara otra y terrenos hay que rinden dos a un tiempo con menoscabo de ambas". No regatea calificativos ni exageraciones el mencionado GONZALEZ DE ZUÑIGA, C. Descripción geográfica, estadistica, económica e historica de la ciudad capital de Pontevedra. Pontevedra, 1848, pp. 17-18, que nos habla de "fertilidad increible" o "fecundidad prodigiosa". Del mismo signo, puede verse la intervención de MUÑOZ en el citado Congreso Agrícola. Santiago, p. 181.

(33) Para PLANELLAS, J., en su intervención en dicho Congreso, y en la p. 154 de las Actas lo reduce a $1 / 4$, como hemos indicado. Similar apreciación en DIAZ DE RABAGO, J. El crédito agrícola. Santiago, 1883, p. 50 al referir que el labrador gallego tiene desterrado el barbecho en la mayor parte de Galicia, aunque domina en Lugo.

(34) Ibidem DIAZ DE RABAGO, J. El crédito...., op. cit. p. 50, relata que se hacen aquí rotaciones antes de que "estas cuestiones fueran entretenimiento de los agrónomos" y dan "variedad a la producción, hacen menos intensas y frecuentes las crisis alimentarias y dejan ya camino abierto a las grandes reformas agricolas".

(35) Cabe mencionar muy en primer lugar a Valenzuela Ozores, un auténtico precursor de las matemáticas sociales. Vid. su magnifica obra Memoria estadistica..., op. cit., pp. 80 y 60 . Duro ataque al mal uso de los cálculos o las falsas deducciones sobre nuestra inferioridad pues, por el contrario, nuestro suelo tiene uuna fecundidad que ojalá tuvieran las demás provincias de España" y así destaca cómo el producto imponible por Ha. es en España de 48,60 reales, mientras que en Pontevedra lo es de 126,30 (p. 82). Asimismo, para el mencionado Planelles (Vid. Actas del Congreso Agricola de 1864, pp. 155 y 172) la agricultura gallega está "más adelantada que la del total del resto de España». Para DIAZ DE RABAGO, J. El crédito...., op. cit., p. 19, cuando combina los datos de población con los de tierra cultivada, llega a la conclusión de que si en 
España la Ha. cultivada sale a 1 habitante, en Galicia esta Ha. debe alimentar a 2; es por ello que considera la agricultura gallega como superior a la española, aunque en retraso con relación a Europa.

(36) Remitimos al Apéndice para el que desee apreciar nuestros cálculos decenales con mayor minucia. Aqui buscamos una mayor representavidad de resultados con esta agrupación.

(37) Aunque se precisan más estudios, no parece que los rendimientos de estas zonas litorales fueran superiores a $5 \times 1$ a comienzos del siglo XVIII. Vid. PEREZ GARCIA, J. M. Un mode10...., op. cit., p. 200 y Apéndice Tabla 5-16.

(38) El paralelo con el cuadrilátero de agricultura evolucionada de que nos habla Le Roy Ladurie es evidente. En el extremo Norte de Francia se habría pasado de unos 23-26 $\mathrm{Hl} / \mathrm{Ha}$. a 28 $29 \mathrm{HI} / \mathrm{Ha}$. Véase LE ROY LADURIE, E. "De la crise...", op. cit. p. 144 y ss.

(39) Algunos coetáneos vieron muy bien estas ventajas de la pequeńa propiedad, cuando no es extrema, frente a los entusiastas seguidores del modelo inglés. Para DIAZ DE RABAGO, J. El crédito...., op. cit., p. 20, esta realidad del minifundio «puede hasta constituir una de las fórmulas de progreso en agricultura" y toma como ejemplo a Flandes el urincón más poblado y de los más subdivididos de la tierra». Como buen maltusiano, contrasta la densidad pontevedres de 100 habs./Km². por entonces, con la gallega de 62,8 y la española de 32,7 y correlaciona población y propiedad.

(40) En 1964, cuando aún no habian triunfado los abonos químicos ni los maizales híbridos, la zona litoral obtenía unos rendimientos medios de maíz de $45,2 \mathrm{HI} / \mathrm{Ha}$. en regadio y 31,3 en secano, sea una media de $38,2 \mathrm{HI} / \mathrm{Ha}$., bastante superiores a los nuestros. Véase Mapas provinciales de suelos. PONTEVEDRA. Ministerio de Agricultura, Madrid, 1964, Apéndice pp. 251-53. Cálculo nuestro realizado a partir de estos datos. Para BOUHIER, A. La Galice...., op. cit., T. II pp. 1.776-78, la elevación de los rendimientos del Sudoeste entre 1752 y 1970 seria de 30 a 60 $\%$ en maices tradicionales, porcentaje inferior al nuestro que situariamos en una cifra próxima al $100 \%$.

(41) GELABERT GONZALEZ, J. E. Santiago y la tierra de Santiago de 1500 a 1640. Tesis de Doctorado Inédita. Univ. Santiago, 1980, obtiene para el área rural de Santiago unos rendimientos de 3 a $5 \times 1$ a partir de "prisées de recoltes" y de 3,3 a $5 \times 1$ tomando como base los Expedientes de Hacienda. En la zona de Caldas, los rendimientos medios eran de 5,6 $\times 1$ a comienzos del siglo XVIII. Vid. EIRAS ROEL, A. «Un vecindario de población y estadística de la riqueza de Galicia en el siglo XVIII. Modelo metodológica para su estudion. Cuadernos de Estudios Gallegos, XXIV, n. ${ }^{\circ} 72-74$, p. 518.

(42) Pueden verse rendimientos aún más optimistas que los nuestros en la comarca de "La Ulla". Vid. REY CASTELAO, O. Aproximación a la Historia rural de la comarca de "La Ulla" (siglos XVII y XVIII). Univ. Santiago, 1981, pp. 107-108.

(43) En 1964, los rendimientos medios en los valles del Ulla y Miño eran de 45,5 HI/Ha. en regadio y de 27,28 en secano. Sea una media global de $36,7 \mathrm{HI} / \mathrm{Ha}$., muy similares a los 38,2 del bloque anterior. Vid. Mapas provinciales....,op. cit., Apéndice, pp. 251-53.

(44) Estos datos confirman los ofrecidos por Pegerto Saavedra para el Burón. Esto parece demostrar que no sólo las tierras occidentales sufrieron estos cambios y que estas zonas viven transformaciones importantes desde fines del siglo XVIII. Vid. SAAVEDRA FERNANDEZ, P. Economia rural...., op. cit. pp. 45-46. El ideal de una agricultura equilibrada de Vicente do Seixo llegaba pues al interior gallego. Para este autor (DE EL SEIXO, V. Lecciones prácticas de agricultura y economia que da un padre a su hijo para que sea un buen labrador en cualquier Pais del Mundo. Madrid, 1792, T. I, p. 228), las tierras de labor sólo son buenas a proporción que se abonan, sólo se abonan a proporción que se hace estiércol, y sólo se hace estiércol según los animales que se tienen y lo bien mantenidos que se hallan".

(45) En efecto, en El Burón y a mediados del siglo XVIII, los rendimientos más generalizados serian de 4 a 6,5 ferrados por ferrado de superficie en la primera calidad, 3,5 a $6 \times 1$ en la segunda y 2,5 a 4 en la tercera. Vid. SAAVEDRA FERNANDEZ, P. Economia rural...., op. cit., p. 38. cuando escribe D. Antonio Salgado hacia mediados del siglo XIX, éste nos señala que las agras producen cordinariamente de cuatro a ocho fanegas cada una que se siembra... y por término medio se cogen sei por una". Vid. Notas de D. Antonio Salgado..., op. cit. 
(46) Asi se desprende de los datos publicados en 1964, según los cuales estas demarcaciones lograban unos rendimientos medios de 37,05 $\mathrm{HI} / \mathrm{Ha}$. en regadio y 25,08 en secano lo que significaba una media de 31,07 Hl/Ha. Vid. Mapas provinciales..., op. cit., pp. 251-53.

(47) Véase Tabla IV y gráfico 1 A y $B$.

(48) Vease gráfica II A.

(49) Vid. también gráfica II B.

(50) La diferencia entre ambas medias consiste en que la primera considera las superficies totales y en la media simple el cálculo se obtiene sobre la cifra media ya calculada para cada demarcación y no tiene en cuenta las superficies relativas de cada zona. En todo caso la diferencia es mínima y este doble cálculo lo hacemos para evitar posibles efectos distorcionadores.

(51) Los propios patrimonios nos confirman esta elevación. En el Memorial de bienes de D. Tomás Fresco, vecino de S. Juan de Bayón, realizado el 1-VIII-1770, se indica una finca de labradio de primera calidad de 3 ferrados de extensión alo que por seren de tan buena calidad producen treynta y seis de mays», sea un rendimiento de $12 \times 1$ para las mejores tierras de las comarcas costeras de entonces. En el memorial de D. Francisco Martinez, vecino de Santa María de Loimil, realizado el 11-VIil-1848, se registra una parcela de 6 ferrados y de primera calidad regadia a la que se le asigna una producción de 96 ferrados, mitad centeno y mitad malz; es decir, un rendimiento de $16 \times 1$ para las mejores tierras del valle del Ulla y a mediados del siglo XIX. Vid. A.H.D.S., Sagradas Ordenes, Patrimonios, Carpetas 7 y 120.

(52) Así, en el patrimonio a favor de D. José Castro, vecino de S. Verísimo de Barro, se senala una finca de 10 ferrados de superficie que rentúa 60 ferrados de malz que perciben los otorgantes de José y Andrés Barosa y otros, así como 3 pares de capones. A.H.P.P., Fondo de Protocolos, G 128 A., A. Chasn y Caldas, 13-VIII-1774. Otro ejemplo podría ser el Inventario y reconocimiento de mayorazgo de D. Francisco Blanco que registra una pieza de labradío de 8,75 ferrados de extensión. Esta pieza la trabaja José Carreira en virtud de arriendo y paga 40 ferrados de maiz, 4 ferrados de diezmo y 4 ferrados de frijoles. A.D.T., Fondo Hospital, Patrimonios, Leg. 1. Por último citemos el Memorial de D. Manuel A. Danza, vecino de S. Mamed de Rois (Padrón), que relata 5 piezas con una extensión de 10 ferrados cultivadas por varios vecinos y que le rentúan 52 ferrados de maíz y centeno. A.H.D.S., Sagradas Ordenes, Patrimonios, Carpeta 116.

(53) La principal discordancia se relaciona con la paralela caida de las series diezmales a partir de 1730-60 para las zonas aquí estudiadas. Vid. EIRAS ROEL, A. "Dîme et mouvement du prodult agricole en Galice (1600-1837)'. Coloquio Internacional sobre el Diezmo y el movimiento de la producción agraria. Paris, 1977.

(54) Galicia, cuya población casi se estanca entre 1752 y 1787 con un crecimiento casi nulo del 3,6 \% en 35 años, sufre una notable aceleración después pasando de 1.345.803 habitantes en 1787 a 1.799.244 en 1860, sea un avance del 33,69 \% en 73 años. Correspondería un aumento del $36 \%$ para las provincias occidentales y un $31 \%$ para.las orientales. Vid. para los primeros cálculos PEREZ GARCIA J. M. y otros. Historia de Galicia. Ad. Alhambra, 1980, p. 163. Para los datos de 1860 véase LOPEZ TABOADA, J. A. Economia y población en Galicia. La Coruña, 1979, p. 97.

(55) Tan sólo en 1753-54 monta ligeramente la curva de defunciones sobre la de nacimientos y ello a pesar del cólera. Esto lleva a BARREIRO MALLON, B. "Demografla y crisis en Galicia durante el siglo XIXw, recogido en EIRAS ROEL, A. y colaboradores. Las Fuentes y los métodos. Univ. Santiago, 1977, p. 217, a afirmar que la mortalidad catastrófica ha desaparecido casi totalmente de Galicia.

(56) Así, para DIAZ DE RABAGO, J. El crédito...., op. cit. p. 42, el rendimiento del maiz «es casi el doble que el del trigo por unidad de superficie y pasa de su triplo en cuanto a la masa totałw. Apreciación sin duda excesiva pero cierta en el fondo. VAENZUELA OZORES, A. Memoria geognóstica-agricola sobre la Provincia de Pontevedra. Madrid, 1856, p. 107, refiere que el maíz es la «verdadera riqueża de la provincia y quizá por lo mismo la mejor cultivada de las plantas». Este último autor confirma también la superior productividad del centeno en los valles superiores pues amultiplica sus frutos una tercera parte más que el trigon (pp. 107-108). 
(57) Nos hacemos así eco de la demanda sistemática de este cálculo, realizada por el maestro de la historia rural MEUVRET, J. "Production et productivité agricoles». III C.I.H.E., Munich, 1965, p. 14.

(58) Sobre una treintena de Respuestas Generales, hemos retenido como valor de semilla los más repetidos en las mismas: 0,75 ferrados de trigo para sembrar un ferrado de superficie, 1 ferrado de centeno para sembrar otro tal de superficle y 3 oncas de maiz para sembrar la citada extensión. No hemos encontrado notables diferencias de una áreas a otras. Tampoco son previsibles cambios importante en el tiempo: la siembra en hileras, que reduce de una manera notoria el grano a sembrar, no llega a Galicia hasta la introducción del maíz híbrido.

(59) Nuestra misión es mucho más optimista que la ofrecida por Fenández de Pinedo para el País Vasco, cuando, nos indica que los rendimientos del maíz eran dobles o triples a los trigueros y para ello supone un rendimiento de $24 \times 1$ en el maiz, muy inferior al nuestro. Vid. FERNANDEZ DE PINEDO, E. Crecimiento económico y transformaciones sociales del Pals Vasco. 1100/1850. Madrid, 1974, pp. 212-15.

(60) Hemos prescindido de los limitadísimos casos en los que las deducciones son inferiores a 1/3 o superiores a 1/2. En tales ocasiones es normal que el patrimonio especifique el producto bruto de la parcela con lo que no tenemos dificultad alguna.

(61) Dado que el predominio del ferrado de $629 \mathrm{M} .2$ es manifiesto en esta muestra (77 a 78 $\%$ de los casos) hemos retenido esta extensión. La desviación que cometemos es mínima y esta seria, en todo cas, negativa para los rendimientos por la menor extensión del ferrado de superficie tudense. En cuanto a las medidas vitícolas de capacidad retenemos el mollo de $140 \mathrm{I}$., media del mollo de 72 azumbres (144 I.) y el de 68 (136 I.), utilizados casi por mitad en las comarcas aqui estudiadas.

(62) Discrepamos de los cálculos de BOUHIER, A. La Galice...., op. cit. T. II, pp. 1.195-98. El autor considera unos rendimientos medios de $20 \mathrm{HI} / \mathrm{Ha}$. para 1752 y fija una ocultación no controlada de un $25 \%$ en el Catastro. Para la actualidad este autor y para estas tierra del Sudoeste, registra 45 a $60 \mathrm{HI} / \mathrm{Ha}$. y considera normales los $60 \mathrm{HI} / \mathrm{Ha}$. en cepas tradicionales. (Estas cifras resultan bajas si las contrastamos con las de HUETZ DE LEMPS, A. Vignoles et vins du Nord-ouest de l'Espagne, p. 150, situadas entre 60 y $80 \mathrm{HI} / \mathrm{Ha}$.). Es por ello que aquél establece una subida desde 1752 a hoy del 50 al $85 \%$ e incluso se desprenderia una elevación superior con sus propios datos. Nosotros consideramos que la elevación no ha podido ser tan fuerte a nivel de cpas tradicionales y que el punto de partida de 1752 está situado muy por debajo de lo real. El mismo autor admite que los vecinos de S. Juan de Albeos (Creciente) y con un ferrado reducido de $437 \mathrm{~m} .2$ declararon en 1752 una producción de $73 \mathrm{HI} / \mathrm{Ha}$. en la primera calidad, $36 \mathrm{HI} / \mathrm{Ha}$. en la segunda y 18,30 en la tercera (p. 1.197). ¿Se equivocaron estos vecinos perjudicándose a si mismos?.

(63) Vid. LABROUSSE, E. Fluctuaciones económicas e Historia social. Madrid, 1973, en especial pp. 445-46. Los años cálidos en torno a 1780 han determinado grandes cosechas vitícolas, como sucedió entre 1778 y 1781 por ejemplo. Vid. DESAIVE, J. P. y otros. Medecins, climat et épidémies à la fin du XVII/• siècle. París, 1972, pp. 56-57. Para una visión más amplia en el tiempo, puede verse LE ROY LADURIE, E. Les paysans...., op. cit., p. 38 y Apéndice gráfico 1. EI autor no duda en afirmar que fueron los ciclos cálidos del siglo XVIII, los que estimularon la producción vitícola, siendo los auténticos responsables de la crisis de superproducción prerevolucionaria visible desde 1778. Los precios vitícolas gallegos reproducen a la perfección el ciclo de bajos precios labroussiano. De un precio medio cíclico de 536 maravedis para 1755-69, se pasa a otro de 458 para el de $\mathbf{1 7 7 0 - 9 0}$ en plena fase de alza generalizada de los precios agrícolas. Vid. PEREZ GARCIA, J. M. Un modelo...., op. cit., pp. 273-74.

(64) Sobre este punto Vid. HUETZ DE LEMPS, A. Vignoles...., op. cit., pp. 520-21, quien sitúa el efecto del oidium entre 1855 y 1862 , causante del abandono de la vid en favor de otros productos. Ya BOUHIER, A. La Galicie...., op. cit., p. 622, ha destacado que tal crisis viene precedida por un período de retroceso-contraste del Catastro con los datos de Madoz-debido a la pérdida de mercados y a la concurrencla catalana. Más datos sobre la mencionada crisis en RODRIGUEZ GALDO, M. J.- DOPICO, F. Crisis agrarias y crecimiento económico en Galicia en el siglo $X I X$. La Coruña, 1981, p. 121. 
(65) Hemos traducido, pues, los carros de tojo, madera o hierba con sus correspondientes cotizaciones a reales, a fin de establecer una base comparativa común. Estas cantidades tienen siempre el carácter de netas porque de ellas ya han sido deducidos las rentas y gastos de cultivo. Estas deducciones no quedan precisadas en nuestros patrimonios.

(66) Hemos utilizado los precios del Salnés por ser las series hoy disponibles que más se remontan en el siglo XIX procediendo de épocas precedentes. Para el corto período de 1841-48 nos hemos valido de los precios de Santiago (Vid. BARREIRO FERNANDEZ, J. R. El levantamiento gallego de 1846 y el nacimiento del galleguismo. Santiago, 1977, p. 19).

(67) En esta tabla, como en las que siguen, no hemos realizado diferencias geográficas, dada la escasa cantidad de parcelas disponibles. Las hemos agrupado en una tabla común para disponer de unas cifras más representativas.

(68) Vid. gráfico III comparando el conjunto de estas variables.

(69) Es evidente que el movimiento alcista de los precios cerealeros gallegos se adelanta y es mucho más intenso que el castellano. Si entre 1700 y 1800 los precios se duplican en Castilla la Nueva, en Santiago y Mondoñedo casi se cuadriplican. Para una visión más detenida y las posibles explicaciones de ello, véase EIRAS ROEL, A.-USERO GONZALEZ, R. "Precios de los granos en Santiago de Compostela y Mondoñedo: siglo XVIII". En III Jornadas de Metodología Aplicada de las Ciencias Historicas. T. III, Univ. Santiago, 1975, pp. 661-63.

(70) Nuestros patrimonios confirman estos altos precios. Así a fines del siglo XVIII y comienzos del $X \mid X$ el precio del carro de hierba se sitúa entre 40 y 60 reales y, aún después de la caída de los precios a partir de 1817, en los años veinte y treinta alcanzaba de 28 a 30 reales. Carecemos de datos para epocas precedentes.

(71) No es frecuente encontrar producción de hierba en los patrimonios, pero creemos que ello obedece sencillamente a que ésta es beneficiada por el colono arrendatario, que es el que trabaja las tierras del patrimonialista. Esta es la forma de aprovechamiento que liga los contratos de aparcería. Claro que en casos excepcionales se registra la producción de hierba. Asi en el Patrimonio de D. Pedro Corbacho, vecino de San Andrés de Geve, se registra una pieza de 6 ferrados de labradío de primera calidad que produce 48 ferrados de maiz, 2 ferrados de habichuelas y uveinte reales que produce de hierba verde"; en el mismo otra parcela de 9 ferrados de primera calidad a la que se asignan 40 reales de hieba verde. A.H.D.S., Sagradas Ordenes, Patrimonios, Carpeta 114, 4-V-1835. También podríamos presentar otro caso, esta vez de la Galicia de transición al interior y de fecha más temprana, como sucede con el Patrimonio a favor de D. Ramón Gamallo, que especifica una pieza de 7 ferrados de labradío de primera la cual produce de medias 18 ferrados de maiz, 3 ferrados de habichuelas, 6 carros de alcacer-seguramente un trozo de la finca destinado a esto-y 20 carros de pastos. A.H.D.S., Sagradas Ordenes, Patrimonios, Carpeta 57, 15-IV-1805. En fecha tan temprana como 1749 encontramos ya alguna declaración parecida como serla el caso del Patrimonio de Manuel de Rubial, vecino de Santa Marla de Perdecanai (Barro), en el que se afirma que una pieza de labradio de 4 ferrados de extensión rentúa libres 20 ferrados de maíz que a 4 reales suponian 80 reales y además produce ude hierba antes de sembrarse veinte reales». A.D.H.S., Sagradas Ordenes, Patrimonios, Carpeta 3, 23-IX1749. No creemos que estas valoraciones de hierba pueden derivar de pasto natural-apréciese cómo en la última valoración, por ejemplo, ésta equivale nada menos que a cinco ferrados de maiz-y asi creemos que en estas tierras de primera calidad los prados artificiales temporales para pastos eran conocidos por entonces.

(72) Los testimonios son, sin embargo, contradictorios. Para PARDO BAZAN, J.-CONDE DE PALLARES. Memoria sobre la necesidad de establecer escuelas de Agricultura en Galicia. Madrid, 1862, pp. 26-27, se debería a la Real Academia de Agricultura "la perfección de la siembra del maíz" y también seria ella la que "distribuyó entre los socios varias semillas, entre ellas la del Ray-grass que llama tanto la atención de los agricultores». No parece que la acción de esta institución fuera tan eficaz (Vid. DOPICO, F. A llustración e a Sociedade Galega. Vigo, 1978, pp. 50-51). VALENZUELA OZORES, A. Memoria agronómica o consideraciones sobre el mejoramiento forestal, practicola y pecuario de la Provincia de Pontevedra. Pontevedra, 1866, P. 13, nos dice que aunque se whacen ensayos de prados artificiales, pero estos son sólo excepciones 
del cultivo general " y más tarde señala que "se carece casi totalmente de prados artificiales" ( $p$. 115). El mismo autor parece contradecirse cuando afirma en la misma obra que el ray grass es una gramínea muy frecuente en nuestros prados (p. 120), que el trébol encarnado se cultiva solo o asociado al ray grass, avena, centeno o nabos (p. 131) y que la serradela ues muy conocida en nuestra provincia donde constituye algunos prados artificiales» (p. 134). ¿Es que el autor cuando nos habla de escasez se está refiriendo tan sólo a los prados artificiales permanentes?. El mencionado CONDE DE PALLARES en su Informe presentado a la junta de agricultura de la Provincia de Lugo. Lugo, 1862, pp. 30-32, propugna como el anterior el desarrollo de los prados artifjciales señalando que el trébol es amuy conocido pero mal cultivadon. En fechas un poco anteriores GONZALEZ DE ZUÑIGA, C. Descripción geográfica...., op. cit., p. 45, nos cuenta, refiriéndose a Pontevedra, que ehay muchos prados naturales y artificiales y no pocos bravios en los que se cevan, crían y mantienen mucho, grande y hermoso ganado vacuno, caballar, mular, cabrio y lanars.

(73) BOUHIER, A. La Galice...., op. cit., T. I, pp. 695-700, sitúa la aparición del ray-grass en fechas no anteriores a 1820 -30 y que la sustitución de la ferraña por esta graminea y la serradela es un fenómeno que data todo lo más de 120 años acá. Si el autor comprueba que hacia tales fechas ya se vendian estas semillas en algunos mercados litorales, creemos que ello refleja ya una cierta vulgarización y no los comienzos.

(74) VALENZUELA OZORES, A. Memoria agronómica...., op. cit., pp. 209-10, ofrece esta interesante apreciación, cuando contrasta la raza vacuna montañesa con la de los valles y costas donde ula abundancia de alimento, el cuidado y aseo de los establos y la educación más inteligente distingue a los habitantes de los valles y costa" lo que determina "que la raza de montaña es más a propósito para el trabajo, mientras que la de los valles lo es para engrasar». No podía escapar a un escritor tan cuantitativista el marcar de forma precisa tales diferencias. Asi afirma que los bueyes de las primeras zonas no exceden de un peso de 550 a 600 libras, en tanto que en los valles alcanzan de 700 a 1000 y la producción de leche también es mayor en estos últimos.

(75) Vid. las obras mencionadas en la nota 29 del presente estudio. También LUCAS LABRADA, J. Descripción económica del Reina de Galicia. Vigo, 1971, en diversos pasajes de su obra.

(76) Algún que otro patrimonio nos confirma esta situación. Así en el patrimonio realizado, a favor de D. Pascual de la Fuente, vecino de S. Mamed de Portela (Barro), se recoge una pieza de 7 ferrados a tojal, robleda y salgueiral la cual por su calidad y wescasez manifiesta que hay de maderas y no necesitar cultura produce...." 200 reales. A.H.D.S., Sagradas Ordenes, Patrimonios, Carpeta 52, 14-X-1802. Es asi que en el Catastro en carro de tojo es valorado en torno a los 2 reales; poco después de nuestros patrimonios ya se cotiza entre 4 y 6 reales para los anos sesenta y setenta, cifra que ya se había trasformado en 10 a 12 para la última década del siglo XVIII y primera del XIX y esto equivalía nada menos que a la cotización que tenía un ferrado de maiz por entonces.

(77) Para la entrada y desarrollo de la introducción del pino Vid. BOUHIER, A. La Galice...., op. cit., T. II, p. 1.030 y SS.

(78) A mediados del siglo XVIII y según el Catastro estos precios se situaban entre 3 y 5 reales el carro; en los ańos sesenta ya se cotizaba a 6 reales, en los anos setenta a 10-11 reales; a fines del siglo XVIII y comienzos del XIX a 15-16 reales, y en los años veinte y treinta superaba los veinte reales con frecuencia. La escalada es sin duda importante.

(79) Sobre este necesario equilibrio ya hemos insistido en otra ocasión. Véase PEREZ GARCIA, J. M. Un modelo...., op. cit., p. 160. El papel del tojal y del monte en la agricultura gallega ha sido magistralmente desarrollado por los geografos. GARCIA FERNANDEZ, J. Organización del espacio y economia rural en la España Atlántica. Madrid, 1975, p. 224y ss., ha visto de forma muy perspicaz este papel del tojo, de tal manera que "la clave de la explotación intensiva del suelo descansa en Galicia en el monte". BOUHIER, A. La Galice..., op. cit., p. 923, indica incluso que existen reglas prácticas que determinan la relación que debe existir entre las superficies cultivadas y las de esquilmo. Los patrimonios reflejan este hecho como consta en el Patrimonio de D. Gregorio Martínez, vecino de S. Martín de Louxame, cuando sobre una parcela de 8 
ferrados a tojal y xestal se estima una producción neta de 36 reales por "tener mucha estimación en el paragen. A.H.D.S., Sagradas Ordenes, Patrimonios, Carpeta 7, 3-VIII-1765.

(80) Es evidente que esta intensificación ya era triunfante a mediados del sigio XVIII en las áreas que limitaban o conformaban la propia dorsal gallega, como sucedia con la Jurisdicción de Caldevergazo. Vid. BUGALLO VIDAL, E. La antigua Jurisdicción de Caldevergazo. Un estudio socioeconómico. Tesis de Licenciatura Inédita. Univ. Santiago, 1979. Claro que ello se obtenía al precio de unos débiles rendimientos de $5 \times 1$ en primera calidad, $3 \times 1$ en segunda y 2 ferrados en tercera. ¿Ocultación o realidad?.

(81) Los arrendamientos notariales incluso llegaban a precisar las condiciones de su abonado y las Respuestas Generales nos informan de que recibían nada menos que tres cavas en el año. Vid. PEREZ GARCIA, J. M. Un modelo...., op. cit., p. 117.

(82) Consideramos que la apreciación de Slicher van Bath es concordante con nuestras conclusiones, cuando correlaciona las áreas densamente pobladas y las fases de precios altos del grano con unos elevados rendimientos. Asimismo colncidimos en la correlación entre avance de la población y el correlativo de los rendimientos. Vid. SLICHER VAN BATH, B. H. "La agricultura en la revolución vital», op. cit., pp. 102-105. 